\title{
Molecular motions that shape the cardiac action potential: Insights from voltage clamp fluorometry
}

24 Wandi Zhu ${ }^{a}$, Zoltan Varga ${ }^{\text {b }}$, Jonathan R. Silva ${ }^{\text {a, * }}$

Q1 a Department of Biomedical Engineering, Washington University in St. Louis, St. Louis, MO, USA

${ }^{\mathrm{b}}$ MTA-DE-NAP B Ion Channel Structure-Function Research Group, RCMM, University of Debrecen, Debrecen, Hungary

\section{A R T I C L E I N F O}

Article history:

Received 16 September 2015

Received in revised form

11 November 2015

Accepted 16 December 2015

Available online $\mathrm{xxx}$

\section{Keywords:}

Voltage clamp fluorometry

Action potential modeling

Sodium channels

Calcium channels

Potassium channels

\begin{abstract}
A B S T R A C T
Very recently, voltage-clamp fluorometry (VCF) protocols have been developed to observe the membrane proteins responsible for carrying the ventricular ionic currents that form the action potential (AP), including those carried by the cardiac $\mathrm{Na}^{+}$channel, Nav1.5, the L-type $\mathrm{Ca}^{2+}$ channel, Cav1.2, the $\mathrm{Na}^{+} / \mathrm{K}^{+}$ ATPase, and the rapid and slow components of the delayed rectifier, $K_{V} 11.1$ and $K_{V} 7.1$. This development is significant, because VCF enables simultaneous observation of ionic current kinetics with conformational changes occurring within specific channel domains. The ability gained from VCF, to connect nanoscale molecular movement to ion channel function has revealed how the voltage-sensing domains (VSDs) control ion flux through channel pores, mechanisms of post-translational regulation and the molecular pathology of inherited mutations. In the future, we expect that this data will be of great use for the creation of multi-scale computational AP models that explicitly represent ion channel conformations, connecting molecular, cell and tissue electrophysiology. Here, we review the VCF protocol, recent results, and discuss potential future developments, including potential use of these experimental findings to create novel computational models.
\end{abstract}

๑) 2015 Published by Elsevier Ltd.

\section{Introduction to voltage-clamp fluorometry}

Nanoscale movements within cardiac ion channels fundamentally determine cardiac action potential (AP) dynamics (Hille, 2001). Genetic mutations (Shah et al., 2005), post-translational modification (Hund and Mohler, 2014), and drug binding (Heist and Ruskin, 2010) perturb these movements to alter channel function, causing or preventing deadly cardiac arrhythmias. Despite much progress in understanding how channels sense voltage and selectively allow ions to cross into and out of the cell, the conformational changes that determine AP dynamics are not welldefined. A method known as voltage-clamp fluorometry (VCF) allows simultaneous observation of changes in channel conformation and ionic current kinetics, and very recently, VCF protocols have been established for major cardiac ionic currents including the cardiac $\mathrm{Na}^{+}$current $\left(\mathrm{I}_{\mathrm{Na}}\right)$, the L-type $\mathrm{Ca}^{2+}$ current $\left(\mathrm{I}_{\mathrm{Ca}, \mathrm{L}}\right)$, the rapid and slow components of the delayed rectifier $\mathrm{K}^{+}$currents $\left(\mathrm{I}_{\mathrm{Kr}}\right.$ and $\mathrm{I}_{\mathrm{KS}}$ ), and the $\mathrm{Na}^{+} / \mathrm{K}^{+}$ATPase ( $\left.\mathrm{I}_{\mathrm{NaK}}\right)$. Here, we will review the VCF

* Corresponding author. Washington University in St. Louis, Campus Box 1097, 1

E-mail address: jonsilva@wustl.edu (J.R. Silva).

protocol, recent results, and how these findings might be incorporated into computational models to better understand how the nanoscale movements of cardiac ion channels determine the dynamics of myocardial excitation.

\subsection{The VCF protocol}

Cardiac ion channels are typically formed by homologous subunits or domains that comprise six transmembrane-spanning segments (S1-S6). The first four segments (S1-S4) form the voltage-sensing domain (VSD), and segments S5-S6 form the channel pore (Ganetzky et al., 1999; Gellens et al., 1992; Itoh et al., 1998; Long et al., 2005; Qin et al., 2002). Within the VSD, the S4 segment contains positively charged amino acids that respond to changes in the membrane potential to control pore conformation through the S4-S5 linker (Aggarwal and MacKinnon, 1996; Bezanilla, 2008; Liman et al., 1991; Seoh et al., 1996). VCF was first used to observe the prototypical Shaker $\mathrm{K}^{+}$channel VSD with a fluorophore tethered to the S4 segment (Mannuzzu et al., 1996). As the environment surrounding the $\mathrm{S} 4$ was altered by VSD movement in response to changes in membrane potential, the fluorescence emission from the tethered fluorescent molecule was also altered 
(Fig. 1A). Thus, the change in fluorescence emission could be used to observe the voltage-dependent kinetics of the VSD.

Fluorophore tethering for VCF is typically accomplished by introducing a cysteine residue into the area of interest and labeling it with a thiol-reactive fluorophore. Native cysteines are often removed in order increase the specificity of labeling and reduce background fluorescence (Gandhi and Olcese, 2008). To track VSD conformation, the fluorophore is usually conjugated to a cysteine into the S3-S4 linker (Fig. 1A). The fluorescence signal created by the change in channel conformation is usually quite small, so large numbers of channels must be expressed to observe a useful signal. The Xenopus oocyte is often used as it is well-known to express large numbers of channels from mRNA that is injected into the cytoplasm. The oocyte also has a dark pigmented layer directly beneath the membrane of the animal pole, which eliminates most of auto-fluorescence from cell, allowing for resolvable fluorescence signals (Gandhi and Olcese, 2008). In mammalian cells, the wholecell patch clamp configuration has been combined with semiconfocal epifluorescence microscopy to observe Shaker $\mathrm{K}^{+}$channel conformations (Blunck et al., 2004). However, cardiac channels have not been successfully studied using this method. One challenge to studying these channels is much lower channel density, in comparison to Shaker.

In the oocyte protocol, channels typically express at high levels 3-7 days after RNA injection, and they are subsequently labeled with a thiol-reactive fluorophore, which binds to the introduced cysteine (Fig. 1B). Then, ionic currents and fluorescence emission can be recorded using the two-electrode or cut-open oocyte Vaseline gap (COVG) voltage-clamp configuration. The COVG configuration provides faster clamping and lower noise, and is commonly applied to observe $\mathrm{Ca}^{2+}$ and $\mathrm{Na}^{+}$channel currents whose fast kinetics are physiologically pertinent (Fig. 1B) (Pantazis

A

B
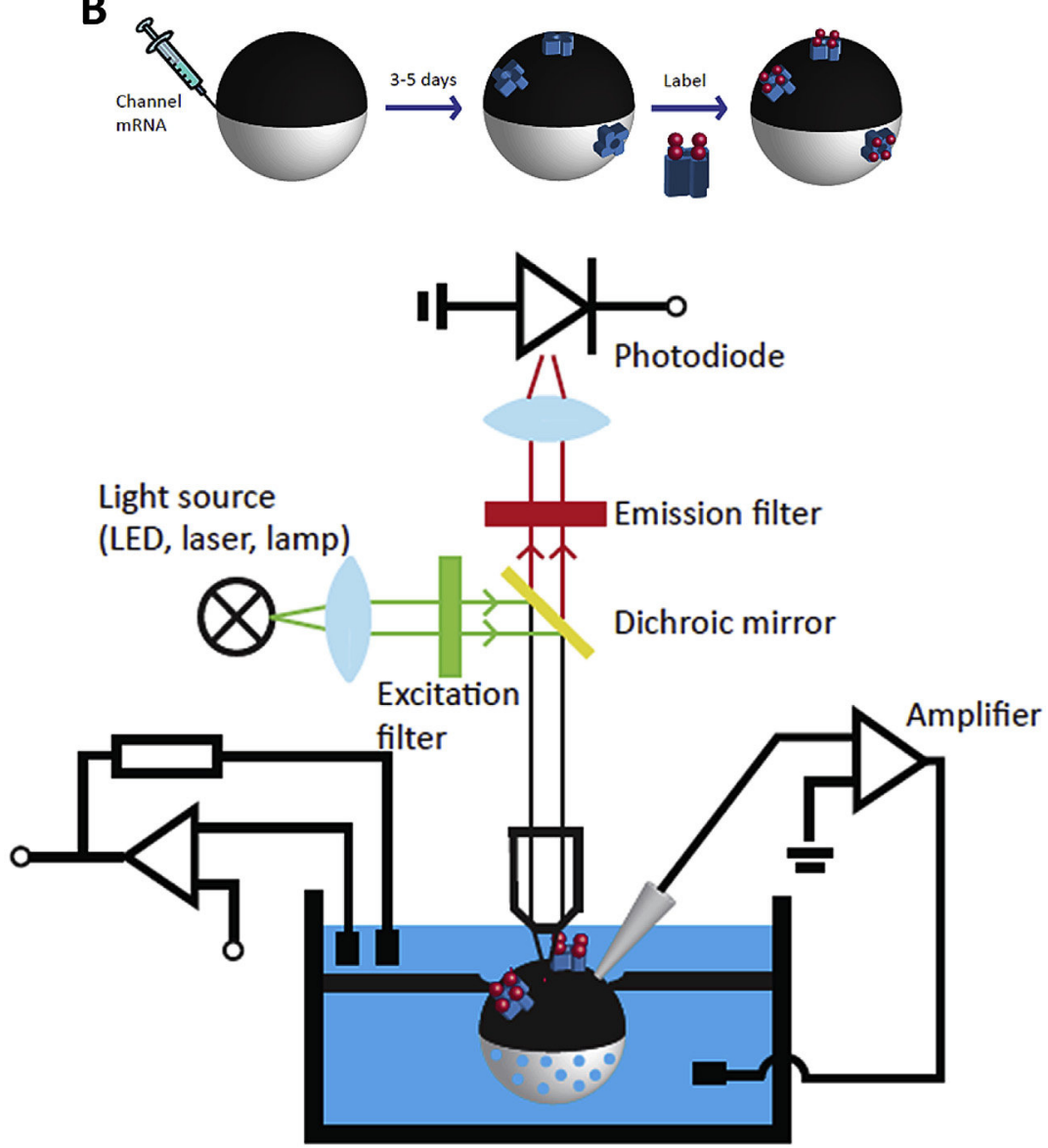

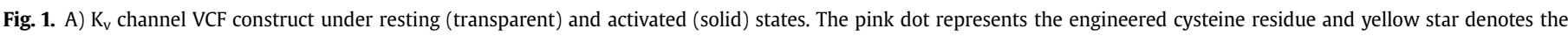

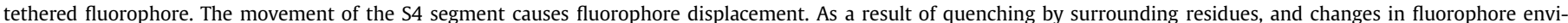

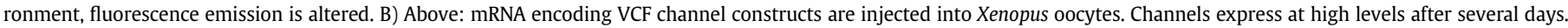

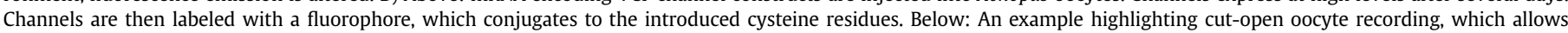

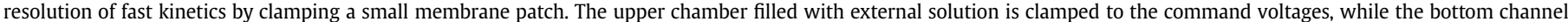

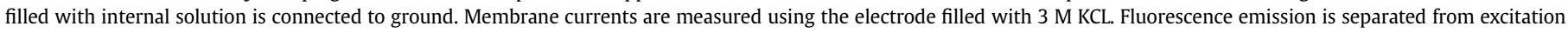
light by a dichroic mirror and filtered by the emission filter. Finally, it is collected with a photodiode that is connected to a low noise current amplifier. 
and Olcese, 2013; Siefani and Bezanilla, 1998). Changes in fluorescence emission are tracked simultaneously with a photodiode (Cha et al., 1999a; Rudokas et al., 2014) that is coupled to a patch clamp amplifier or by a photomultiplier tube (Mannuzzu et al., 1996).

There are multiple physical mechanisms that could underlie the observed changes in fluorescence. First, displacement of the fluorophore upon VSD activation could enable the fluorophore to move from a lipid environment to the extracellular solution, resulting in fluorescence quenching and a right shift in the emission spectrum (Blunck, 2015). Second, changes in fluorescence emission can also be caused photo-induced electron transfer, a quenching mechanism where electrons are transferred between two molecules via a non-radiative path could reduce fluorescence emission as the fluorophore approaches a quenching molecule (Doose et al., 2009, 2005; Marmé et al., 2003; Vaiana et al., 2003). This transfer typically occurs within the van der Waals radius (10 $)$, and the amount of quenching varies between amino acids. Tryptophan and tyrosine are usually the most potent quenchers (Chen et al., 2010). In support of the latter mechanism, VCF in Shaker $\mathrm{K}^{+}$channels showed no shift in the spectrum of fluorescence emission, implying that a change in solvent environment is not responsible for the fluorescence signal in these experiments (Cha et al., 1999b). As it is currently not possible to reliably predict how a fluorophore at a particular position will be quenched, development of VCF DNA constructs often requires cysteine scanning of multiple positions for fluorophore labeling. If multiple labeling sites produce usable signals, the labeled cysteine that minimally perturbs the channel function is typically chosen. Further, the location of the optimal labeling site can depend on the fluorophore's properties, including its solubility, the length of the carbon chain that connects the fluorophore to the thio-reactive group, and its charge content (Hughes et al., 2014).

\subsection{Limitations}

While VCF has already provided significant insight into the gating mechanisms of many channels, it is important to note that as with any experimental protocol, there are limitations. VCF probes channel conformation by observing fluorescence change, which as described above can be caused by different mechanisms (Cha and Bezanilla, 1997; Chen et al., 2010). As a result, the fluorescence change may not be related by a linear function to the distance moved by the $S 4$ segment, but instead may be a complex function of multiple factors, including the movement of other nearby domains containing quenching residues, conformational changes within the S4 segment from an $\alpha$ to $3_{10}$ helix (Chakrapani et al., 2010; Long et al., 2007), and non-linear distance dependence of quenching effects (Lakowicz, 2006). Different fluorophores can also reveal distinct components of the S4 movements. For example in homomeric KCNQ1 channels, Alexa 488 tracks the fast component of S4 movement that occurs at hyperpolarized potentials, while a slow movement that occurs at depolarized potentials is dominant in the signal produced by Alexa 546 (Zaydman et al., 2014). It also can be challenging to identify a labeling site, because many positions are not proximal to quenching residues and do not undergo changes in solution environment. This difficulty has been addressed by introducing a quenching tryptophan nearby (Islas and Zagotta, 2006; Mony et al., 2015; Pantazis and Olcese, 2012).

Another potentially confounding effect occurs when the fluorophore enters the electric field, allowing changes in membrane potential during voltage clamp protocols to cause rearrangement of the fluorescent molecule. This phenomenon, known as the electrochromic effect (Klymchenko and Demchenko, 2002), can be identified by its rapidity, which tracks the voltage clamp, and linearity-signals do not saturate with increasing voltage. The electro-chromic effect is most often observed when the fluorophore is not well-quenched by the above mechanisms, resulting in a very small or no signal generated by the conformational change.

Background fluorescence is another common difficulty. Because the fluorescence signal is often small ( $<1 \%$ of the total), high levels of background fluorescence can preclude useful measurements. This problem is exacerbated in channels with many extracellular cysteines, where non-specific sulfide binding of the fluorophore increases background levels significantly. To reduce the background in these channels and preclude di-sulfide bonds between the introduced and native cysteines, it is sometimes necessary to remove cysteines from the protein backbone, which can alter channel function (Osteen et al., 2012; Ruscic et al., 2013).

Moreover, because it is difficult to access intracellular sites, VCF is mostly limited to tracking conformations of extracellular domains. The development of patch clamp fluorometry and fluorescent un-natural amino acid labeling does allow access to intracellular sites (Zheng and Zagotta, 2003, 2000). However, these methods are still being developed, and it is not clear whether they will be universally applicable.

Finally, VCF is most often applied in the Xenopus oocyte expression system, where channels may exhibit different phenotypes than native cardiac myocytes (Abriel, 2007). All heterologous expression systems have drawbacks, and it is thus necessary to confirm that channel phenotypes are consistent with what is observed in native cells. In our experience, the phenotypes are quite often similar, implying that the conformational changes observed in VCF are likely consistent with the conformational changes occurring in native cells.

\section{Overview cardiac channel VCF results}

VCF has been applied to study the conformational rearrangements of many different ion channel families. We will focus on recent VCF findings that reveal mechanisms of cardiac channel gating, post-translational regulation, and the molecular pathologies of arrhythmia.

\subsection{Cardiac sodium channel $N a_{v} 1.5$}

The cardiac voltage-gated sodium channel $\left(\mathrm{Na}_{\mathrm{v}} 1.5\right)$ initiates depolarization of atrial and ventricular action potentials. Mutations within $\mathrm{Na}_{\mathrm{v}} 1.5$ can cause Long QT syndrome (LQT) (Wang et al., 1995), Brugada syndrome (Brugada and Brugada, 1992), sick sinus syndrome (Benson et al., 2003), and atrial fibrillation (Chen et al., 2007; Darbar et al., 2008). Additionally, $\mathrm{Na}_{\mathrm{v}} 1.5$ is an important target for anti-arrhythmic therapies; class I anti-arrhythmics target the $\mathrm{Na}_{\mathrm{v}} 1.5$ pore to block $\mathrm{Na}^{+}$flux (Hondeghem and Katzung, 1984). Functional $\mathrm{Na}_{\mathrm{V}} 1.5$ channels can be formed by monomers, and each of these contain four homologous domains that are formed by six transmembrane segments (S1-S6) (Gellens et al., 1992). As in $\mathrm{K}^{+}$ channels, S1-S4 form a voltage sensing domain (VSD), and S5-S6 form the channel pore. However, unlike $\mathrm{K}^{+}$channels, each VSD in $\mathrm{Na}_{\mathrm{v}} 1.5$ has a distinct amino acid composition, and each plays a different role in regulating $\mathrm{Na}_{\mathrm{v}} 1.5$ gating.

VCF was first applied to skeletal muscle $\mathrm{Na}^{+}$channels (Nav1.4) and has been used to probe VSD interaction with inactivation (Cha et al., 1999a,b; Silva and Goldstein, 2013a, 2013b), local anesthetics (Arcisio-Miranda et al., 2010; Muroi and Chanda, 2009), and toxins (Campos et al., 2008, 2007). To probe similar phenomena in the cardiac channel, we recently developed VCF protocols to track each of the VSDs of Nav1.5. Out of 16 positions attempted, we observed robust signals with DI-V215C, DII-S805C, DIII-M1296C, and DIVS1618C (Varga et al., 2015). Each of the VSDs displayed unique 
voltage-dependent kinetics. The DI, DII, and DIII VSDs each activated much more rapidly than DIV (Fig. 2). Deactivation of DI and DII were also rapid, while DIII- and DIV-VSD deactivation was markedly slower than activation (Fig. 2). To quantify voltage dependence, VSD activation is typically measured by recording peak fluorescence after stepping to various depolarizing potentials, the fluorescence-voltage $(\mathrm{F}-\mathrm{V})$ curve. We observed that the $\mathrm{V}_{1 / 2}$ of the $\mathrm{F}-\mathrm{V}$ curves for each $\mathrm{Na}_{\mathrm{V}} 1.5 \mathrm{VSD}$ is more negative than channel activation (G-V curve) (Fig. 2), suggesting that activation of the VSDs occurs prior to pore opening. The DII-VSD stands out, by completing its activation at higher potentials than the channel conductance, which could suggest that the DII-VSD is a facilitator channel activation whose transition is not absolutely required to open the channel pore (Fig. 2).

VSD activation can also be observed during protocols that measure channel inactivation. A typical steady-state inactivation protocol measures peak $\mathrm{Na}^{+}$current during a test pulse that follows $200 \mathrm{~ms}$ long inactivation-inducing pulses. Significant inactivation occurs at negative potentials during these pulses, before the channel opens. Thus, the protocol is primarily measuring closedstate inactivation. Tracking DIV-VSD conformation during the steady-state inactivation protocol reveals a striking correlation between DIV-VSD activation and closed-state inactivation (Fig. 2) (Varga et al., 2015), similar to previous findings in Nav1.4, where DIV-VSD activation was found to be the rate limiting step of channel inactivation (Capes et al., 2013).

One potential difficulty with VCF experiments is that the detected VSD movement and channel gating may only be spuriously correlated, moving with a similar time and voltage dependence, but without any physical connection. To test whether there is a physical connection between the VCF-detected change in conformation and channel gating in Nav1.5, we introduced point mutations to simultaneously perturb VSD and ionic current kinetics. Then, by observing how the kinetics of VSD activation and ionic current changed in concert, we could begin to define their relationship. Databases of disease-linked mutations provide a guide to locations where channel kinetics are altered, while channel expression is preserved. To test this approach, we introduced two Brugada Syndrome mutations, A735V and G752R, that are found in the DII-VSD (Fig. 3A). We found that the A735V mutation dramatically shifted DII-VSD activation to depolarized potentials, while the G752R mutation significantly slowed DII-VSD kinetics (Fig. 3B) (Varga et al., 2015). The ability of the channel to open at potentials negative to the DII-VSD activation in A735V and at times prior to activation in G752R, confirmed our initial suspicion that the DIIVSD is a facilitator of activation, but is not absolutely required for opening. Moreover, while the ionic current phenotype was similar for both mutants (slowed activation), the molecular phenotype was strikingly different, which could significantly affect the interaction of the channel with therapeutic molecules.

Future work using these $\mathrm{Na}_{\mathrm{V}} 1.5 \mathrm{VCF}$ constructs may reveal details of $\alpha$ subunit interaction with accessory $\beta$ subunits, the molecular pathology of inherited mutations, how class I antiarrhythmic drugs interact with the VSDs, and mechanisms whereby post-translational modifications control channel gating. VCF data will also be tremendously useful for creating computational AP models. For example, traditional, Hodgkin-Huxley type, models imply that each of the channel "gates" must be open before the channel is able to conduct ionic current. This requirement has persisted to date, even in modern Markov type models that simulate complex drug interactions (Moreno et al., 2011). In contrast, the above DII-VSD results imply that the Nav1.5 pore may open even if the DII-VSD gate remains in the resting conformation, which would require an allosteric model. Moreover, the VCF data also provides a molecular connection, revealing specific channel domains that are responsible for the transitions that are represented in the model. Thus, by parameterizing computational models with VCF data, it will be possible to explicitly represent experimentally measured channel conformational dynamics within models of the AP. Such models will be able to connect the molecular dynamics of $\mathrm{Na}_{\mathrm{V}} 1.5$ channel gating, drug interaction and post-translational modification to the cell and tissue dynamics.
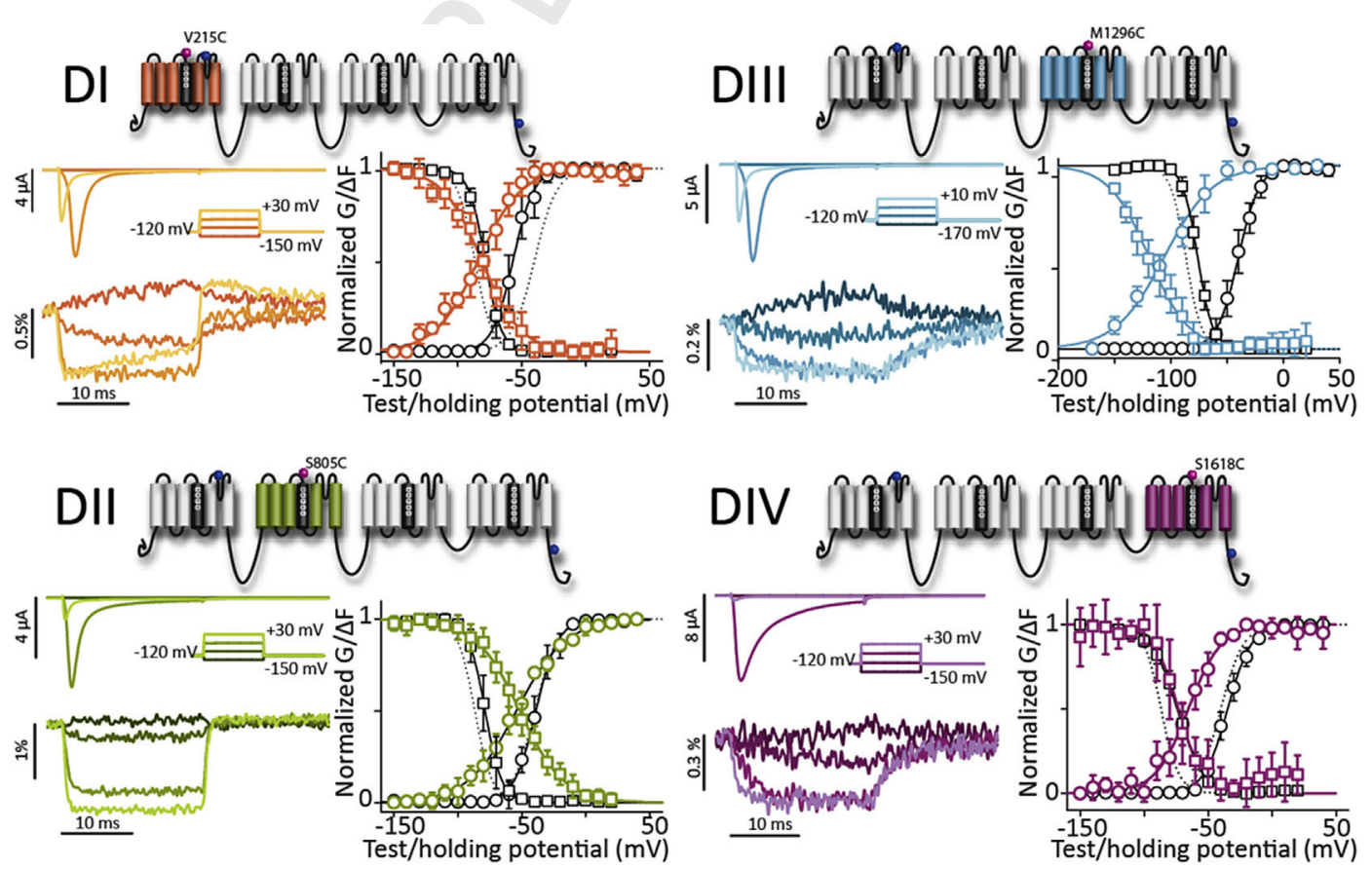

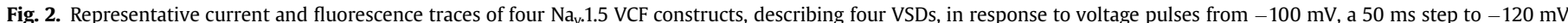

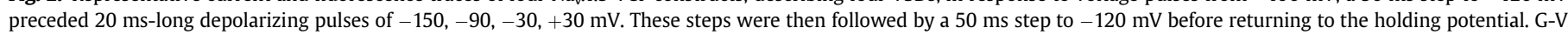
curve (black circles), SSI (black squares), and the corresponding fluorescence voltage relationship F-V curve (color circles and squares, respectively) (Varga et al., 2015). 

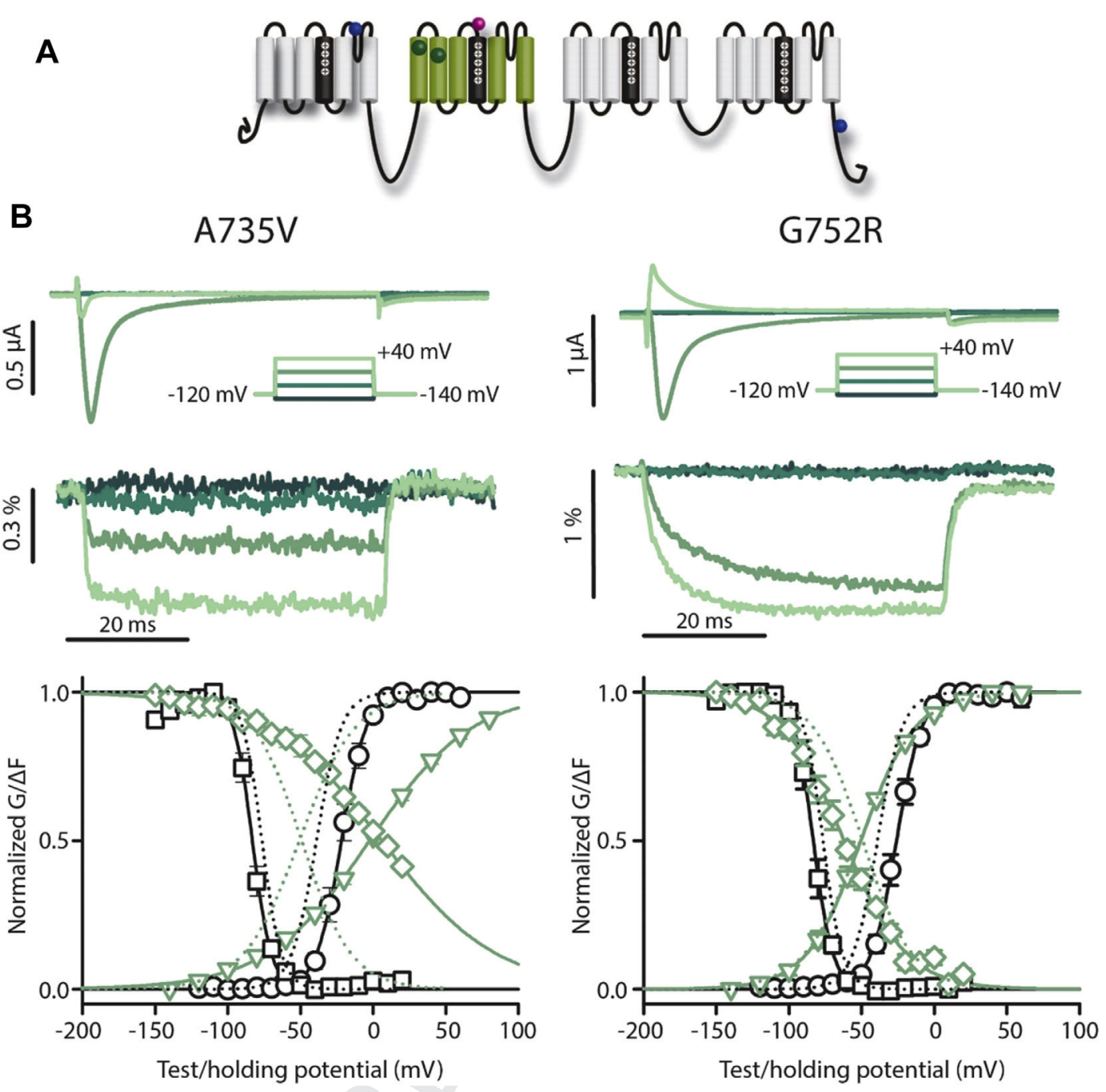

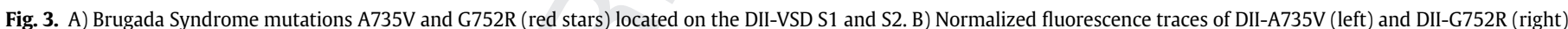

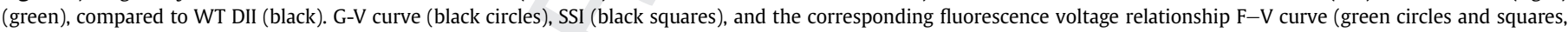
respectively) of DII-A735V (left) and DII-G752R (right) (Varga et al., 2015).

\subsection{L-type calcium channel $\mathrm{Ca}_{v} 1.2$}

The ventricular myocyte AP plateau is primarily maintained by inward $\mathrm{Ca}^{2+}$ flux through the L-type $\mathrm{Ca}^{+}$channel, Cav1.2. This $\mathrm{Ca}^{2+}$ flux induces intracellular $\mathrm{Ca}^{2+}$ release from the sarcoplasmic reticulum, which in turn causes myocyte contraction. Similar to $\mathrm{Na}_{\mathrm{V}} 1.5$, the $\mathrm{Ca}_{\mathrm{v}} 1.2 \alpha$ subunit contains four transmembrane domains (DI-DIV) connected by intracellular linkers, and each is composed of six transmembrane spanning segments S1-S6 with the VSDs formed by S1-S4 and the pore by S5-S6 (Catterall, 2011). $\mathrm{Ca}_{\mathrm{v}} 1.2$ displays two types of inactivation, voltage-dependent inactivation that is mediated by the DI-DII linker and $\beta$ subunit (Van Petegem et al., 2004), and $\mathrm{Ca}^{2+}$-dependent inactivation that is determined by $\mathrm{Ca}^{2+} /$ Camodulin binding to the C-terminus (Imredy and Yue, 1994; Zühlke et al., 1999). Each VSD of the $\alpha$ subunit contributes to the gating charge displacement differently, due to the distinct amino acid sequences for each domain, and asymmetrical modification by auxiliary subunits (Davies et al., 2007; Hidalgo and Neely, 2007; Minor and Findeisen, 2010).

Recently, VCF constructs were developed to track the VSDs of $\mathrm{Ca}_{\mathrm{V}} 1.2$ (DI-F231C, DII-L614C, DIII-V994C, and DIV-S1324C), revealing that each VSD displays different voltage-dependent activation kinetics (Fig. 4A) (Pantazis et al., 2014). The VSDs in DII and DIII activate most rapidly, comparable to the time required for channel pore opening, suggesting that these two VSDs are the ratelimiting step for $\mathrm{Ca}_{\mathrm{v}} 1.2$ channel activation (Fig. 4B). In contrast, DIVVSD activation is the slowest, indicating DIV-VSD may be involved in voltage-dependent inactivation (Fig. 4A), similar to the VSD roles observed in $\mathrm{Na}^{+}$channels.

Due to the distinct time and voltage-dependence of each VSD, the time course of $\mathrm{Ca}_{\mathrm{V}}$ current is poorly predicted using an obligatory model, where activation of all VSDs is required for pore opening. Instead the VCF data is more consistent with an allosteric model where each VSD facilitates pore opening to a different degree (Fig. 4B). This allosteric model best fits experimental results when pore opening is mainly facilitated by DII and DIII-VSD activation (Pantazis et al., 2014).

Recent work has shown that $\mathrm{Ca}^{2+}$ regulation of $\mathrm{Ca}_{\mathrm{V}} 1.2$ and Nav1.5 is evolutionarily conserved (Ben-Johny et al., 2014). This notion of similar regulation can now be further extrapolated to the VSDs, where allosteric regulation of pore opening by the DII and DIII VSDs in both channel families may regulate channel activation, while slower channel kinetics are affected by DIV-VSD activation.

The Ca 1.2 channel $\alpha_{1}$ subunit is tightly regulated by several 


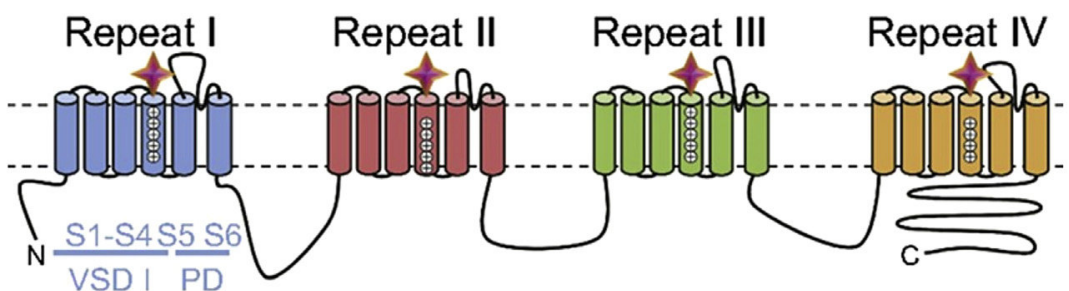

A

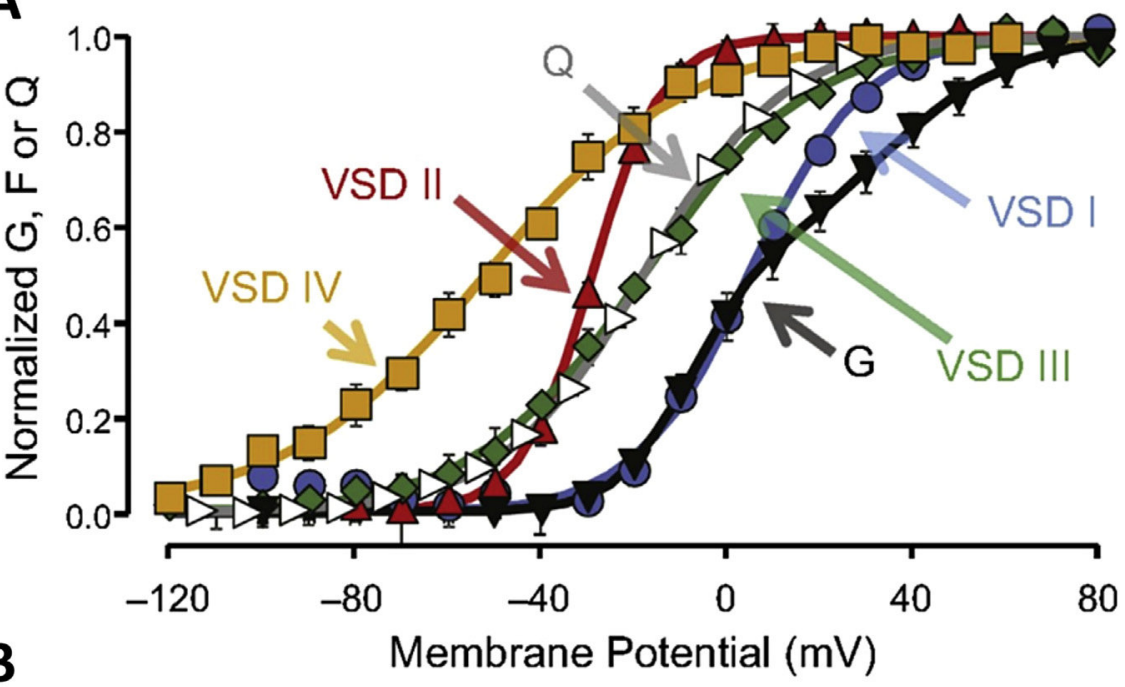

B

Membrane Potential $(\mathrm{mV})$

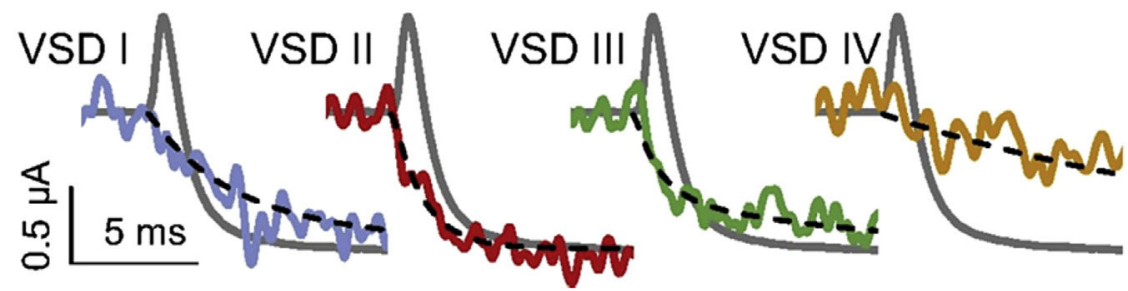

C

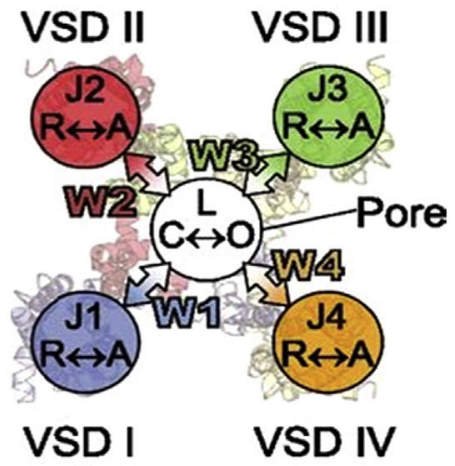

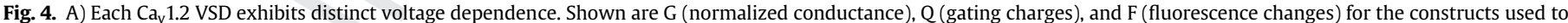

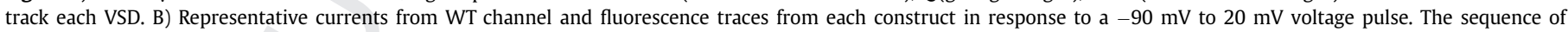

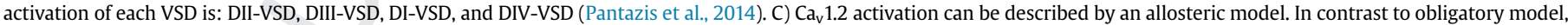
the channel pore can open from any deactivated VSD state. Activation of each VSD contributions energy W to stabilize pore opening.

accessory subunits, including the $\alpha_{2} \delta$ subunits, a $\gamma$ subunit, and multiple $\beta$ subunits $\left(\beta_{1}-\beta_{4}\right)$. These subunits influence channel gating kinetics, charge movement within the channel, and regulation by intracellular signaling molecules (Hofmann et al., 2014). Moreover, heart failure-induced alteration of $\mathrm{Ca}_{\mathrm{V}} 1.2$ interaction with its $\beta$ subunits has been implicated in pathological changes in $I_{C a, L}$ and the action potential (Bodi et al., 2005). Future work has the potential to reveal the molecular mechanisms of these interactions, providing key insight into the regulation of a key physiological and disease-linked $\mathrm{I}_{\mathrm{Ca}, \mathrm{L}}$ transitions.

From a computational perspective, $\mathrm{I}_{\mathrm{Ca}, \mathrm{L}}$ kinetics are central to the behavior of all ventricular AP models (Decker et al., 2009; Faber et al., 2007; Rudy and Silva, 2006), and a VCF-informed model of $\mathrm{I}_{\mathrm{Ca}, \mathrm{L}}$ is likely to be much more predictive than the phenomenological models that are currently used. Moreover, recovery of $\mathrm{I}_{\mathrm{Ca}, \mathrm{L}}$ from $\mathrm{Ca}^{2+}$ - and voltage-dependent inactivation at the end of the AP is 
central to the formation of the early after depolarizations that have been implicated in arrhythmia initiation. Thus, by constructing $\mathrm{I}_{\mathrm{Ca}, \mathrm{L}}$ models based on VCF, the molecular movements that cause arrhythmic tissue-level bifurcations may be identified.

\subsection{Slow delayed rectifier potassium channel Kv7.1}

The two main voltage-gated channels that cause cardiac AP repolarization are the slow $\left(\mathrm{I}_{\mathrm{Ks}}\right)$ and rapid $\left(\mathrm{I}_{\mathrm{Kr}}\right)$ delayed rectifier potassium currents. $\mathrm{I}_{\mathrm{Ks}}$ is carried by the heteromeric complex of the Kv7.1 (KCNQ1, Q1) pore-forming subunit and the KCNE1 (E1) accessory subunit (Barhanin et al., 1996; Sanguinetti et al., 1996), while channels formed by the Kv11.1 (KCNH2) pore-forming subunit and the KCNE2 (E2) accessory subunit conduct $\mathrm{I}_{\mathrm{Kr}}$ (Abbott et al., 1999; Sanguinetti and Tristani-Firouzi, 2006).

The efflux of positively charged $\mathrm{K}^{+}$ions passing through these channels repolarizes the membrane, thereby controlling AP duration. When AP duration is excessively prolonged, patients are diagnosed with Long QT syndrome, and are predisposed to lifethreatening arrhythmias. Such conditions can be caused by loss of function mutations in the pore-forming (LQT1 and LQT2) or accessory subunits (LQT5 and LQT6) of Kv7.1 and Kv11.1 channels (Abbott et al., 1999; Bianchi et al., 1999; Curran et al., 1995; Q. Wang et al., 1996a,b).

Voltage-gated $\mathrm{K}^{+}\left(\mathrm{K}_{\mathrm{v}}\right)$ channels share a similar overall structure with $\mathrm{Na}_{\mathrm{v}}$ and $\mathrm{Ca}_{\mathrm{v}}$ channels, with the major difference that the $\mathrm{K}_{\mathrm{v}}$ channels are composed of four identical or similar subunits that are not connected covalently (Long et al., 2005). Due to this structural difference, $K_{\mathrm{v}}$ channel subunits are thought to function more symmetrically during gating than $\mathrm{Na}_{\mathrm{v}}$ or $\mathrm{Ca}_{\mathrm{v}}$ channel domains.

Early models of voltage-gated $\mathrm{K}^{+}$channel gating were based on the Shaker channel. These linear models assumed that the VSDs moved independently in response to the voltage change, and that full activation of all four VSDs was required for channel opening (Schoppa et al., 1992; Zagotta et al., 1994). Since the link between VSD activation and pore opening in Shaker is very strong, and the latter obligatorily follows the former, these models did not include separate quantities to characterize the coupling between the two events.

VCF has shown that in contrast to these classical Shaker-type mechanisms, KCNQ1 channels have a much looser connection between VSD activation and pore opening. As in Shaker, wild type KCNQ1 VSD activation and channel pore opening have similar voltage-dependence and kinetics. However, mixing mutant channel subunits that shift both the VSD and pore activation left or right on the voltage axis caused separation of the two events and VSD movement could be detected at potentials that were more positive than pore opening (Osteen et al., 2012). Further work revealed VSD motion even in a locked-open KCNQ1 mutant channel, further arguing against an obligatory linear activation mechanism and supporting an allosteric connection between the two domains (Zaydman et al., 2013). In this type of scheme, full activation of all VSDs is not obligatory for pore opening, but the activation of each VSD increases the probability of opening.

The $\mathrm{I}_{\mathrm{ks}}$ current in native cardiac myocytes has dramatically different kinetic and steady-state parameters and pharmacological properties from the pore-forming KCNQ1 current when expressed alone. Association with KCNE1 augments current amplitude, shifts channel opening toward positive potentials by a large amount, and slows opening kinetics (Barhanin et al., 1996; Sanguinetti et al., 1996). The nature of the interaction between the two subunits has been the subject of intense debate. Direct effects of KCNE1 on VSD activation or pore opening have been suggested (Nakajo and Kubo, 2007; Rocheleau and Kobertz, 2008), along with other alternative mechanisms (K. W. Wang et al., 1996a,b). The latest VCF results shed more light on the details of the interaction.

(Ruscic et al., 2013) found that, in contrast to KCNQ1 alone, gating currents could not be recorded in the presence of KCNE1 because of the drastically slowed VSD movement. Similarly to VCF, gating currents provide information about conformational rearrangements of the channel, but report on the global charge movement of the protein rather than local changes in the vicinity of the VSD. In addition, gating currents can become unresolvable during slow transitions, when VCF still produces a measurable fluorescence signal. Thus, using VCF, they observed close correlation between VSD activation and pore opening above $-90 \mathrm{mV}$ in KCNQ1/KCNE1 channels, and concluded that the former is affected by the association with E1 and becomes rate limiting in channel opening. These results question an allosteric gating mechanism and support a Shaker-like linear activation.

However, when VSD movement was observed by two other groups over a wider voltage range starting at more negative values, a large voltage gap was detected between the $\mathrm{F}-\mathrm{V}$ and $\mathrm{G}-\mathrm{V}$ functions, indicating that a significant amount of VSD activation takes place before the channels begin to open (Osteen et al., 2010; Zaydman et al., 2014). Furthermore, two phases of VSD movement during activation were identified: a larger scale, fast movement at negative potentials that carries most of the gating charge, and a smaller, slower one at positive potentials.

The allosteric scheme of Zaydman et al. suggests that the first phase of VSD activation leads to an intermediate state, from which KCNQ1 channels can open in the absence of KCNE1, but not in the presence of KCNE1. Pore opening with KCNE1 occurs only with the activated state of the VSDs, and the permeability properties of the pore differ in the two states due to the different interactions between the VSDs and the pore. This observation explains the higher conductance and altered pharmacology in the presence of KCNE1. The same allosteric scheme describes KCNQ1 gating with and without KCNE1 association, with only the VSD-pore interactions modified in the model by KCNE1. Thus, the model reproduces most of the effects of KCNE1 without assuming any direct influence on VSD activation or pore opening (Zaydman et al., 2014).

Barro-Soria et al. interpreted their VCF data to arrive at a very similar 6-state model (Fig. 5A), in which the four VSDs first move independently, followed by a concerted movement of gating charge in all four subunits during channel opening. As in Zaydman's model, KCNE1 association is assumed to affect the VSD-pore coupling, which manifests as a shift of the main VSD movement to more negative potentials, a shift of pore opening to more positive potentials, and slowed opening kinetics due to the stabilization of the activated closed state (intermediate-closed state in Zaydman's model). In Barro-Soria's model, the second fluorescence component is attributed to the pore opening step (Fig. 5B), which cannot occur before all four VSDs have activated. In contrast, in Zaydman's model the second component represents the intrinsic second phase of VSD movement, which occurs even in the absence of KCNE1; pore opening, albeit with low probability, is allowed before the full activation of all four VSDs.

Thus, despite some remaining differences, the two latest models seem to agree that the observed effects of KCNE1 association can be explained by altered interactions between the VSD and the pore, that is, the coupling between the two functional domains. In particular, the activated-closed (or intermediate-closed) interaction is strengthened by KCNE1 association, meaning that after the first phase of VSD movement the pore is less likely to open in the presence of KCNE1. Zaydman's model uses a coupling constant to characterize each pair of VSD-pore conformations, rather than a single averaged one as in previous models. This way the strength of the activated-open interaction can also be increased, and the model could successfully recapitulate the main features of KCNQ1 gating 
A
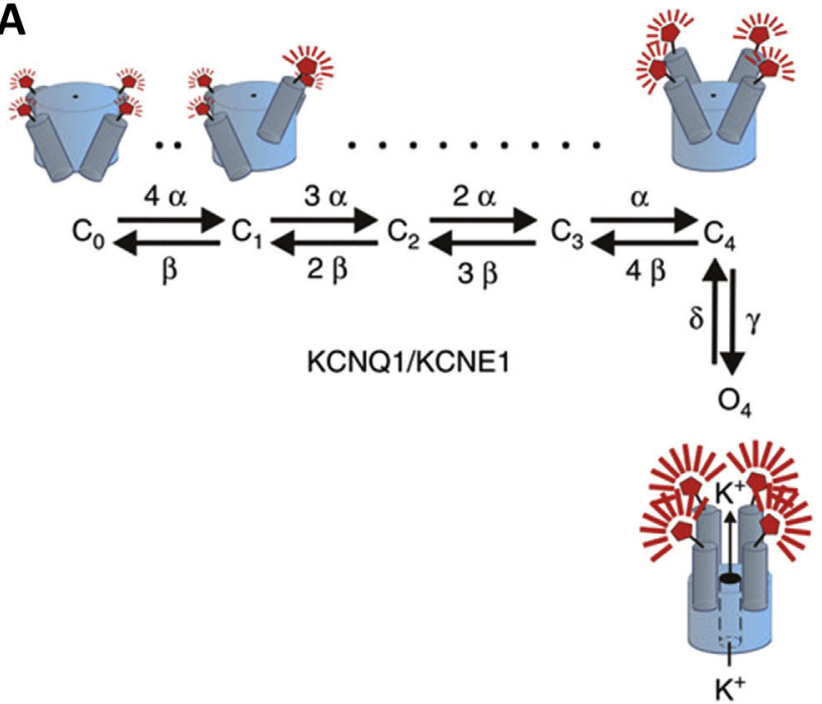

B

KCNQ1/KCNE1
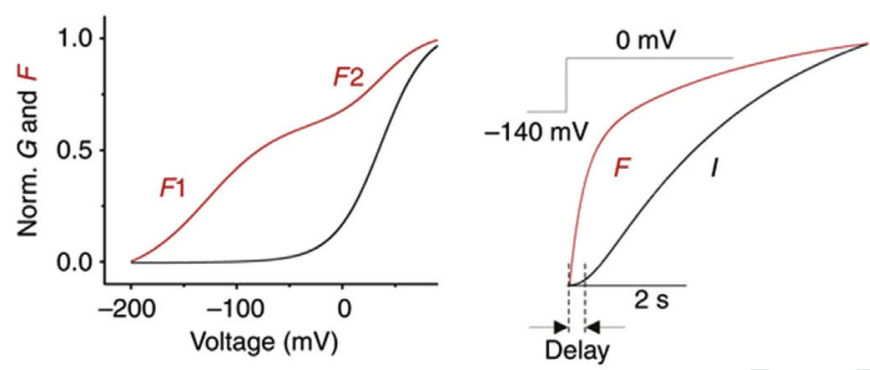

Fig. 5. A) The allosteric gating scheme and the corresponding cartoon representation of Barro-Soria et al. modeling the KCNQ1/KCNE1 complex. The horizontal transitions represent the initial VSD movements carrying most of the gating charge and accounting for the major F1 fluorescence component seen in panel $\mathrm{B}$. The vertical transition represents pore opening accompanied by further VSD rearrangement producing the smaller F2 fluorescence component at more positive voltages. B) The black line showing the voltage-dependence of pore opening calculated from the model is in good agreement with the experimental data and illustrates the large voltage gap between initial VSD activation (red line, fluorescence) and pore opening in the complex. The separation of the activation of the VSD and pore domain is further emphasized by the greatly differing activation kinetics observed both in the experimental and the simulated data (Barro-Soria et al., 2014).

in both the absence and presence of KCNE1.

These new models, which are based on VCF results, illustrate that channel function can be just as drastically altered by the modulation of coupling as by direct effects on VSD movement or pore opening. The mechanism of coupling, which was originally thought of as a rigid protein-protein interaction, now clearly seems to be more complex, in some cases requiring a lipid, while in others not requiring continuity in the channel protein for gating to occur (Lörinczi et al., 2015; Zaydman et al., 2014).

Several ion channels have been shown to be modulated by the anionic phospholipid phosphatidylinositol-4,5-bisphosphate (PIP2), found in the inner leaflet of the plasma membrane (Kruse et al., 2012). Members of the KCNQ family stand out in that they completely fail to conduct current in the absence of PIP2. Membrane lipids in general can affect ion channel function by various means. Beyond the obvious physical changes that are caused by the alteration of the lipid composition, such as in fluidity and mechanical stress, it has become clear that lipids can also interact with ion channels in more specific ways, for example by rearranging the microdomain structure, modifying local electric potential profiles, or even specifically binding to them (Bock et al., 2003; Combs et al., 2013; Martens et al., 2000; Rosenhouse-Dantsker et al., 2013). VCF is well-suited for the study of such phenomena, as effects on the VSD or the pore can be distinguished.

The effect of PIP2 on KCNQ1 channels was studied by coexpressing the lipid-phosphatase CiVSP (Murata and Okamura, 2007; Murata et al., 2005) and activating it by voltage pulses. As VCF showed, depletion of PIP2 by CiVSP did not prevent VSD activation, but it inhibited the ionic current through the channels. The energetics of VSD movement were unaffected, as the voltagedependence of the fluorescence signal was not shifted by PIP2 depletion. A strong effect on the conducting pore caused by the lack of PIP2, together with insensitivity of the VSD movement, indicated a loss of coupling between the two domains. In the presence of PIP2, the F-V curve shifted left, indicating that the open state of the pore induced the movement of the VSD at more negative potentials than normal. When PIP2 was depleted, the shift disappeared, and VSD movement occurred at normal voltages, indicating that the open state of the pore was not communicated back to the VSD. Thus, PIP2 was proven to be an essential cofactor in coupling between the VSD and the pore. Based on mutational data and homology modeling, they proposed a general model, in which PIP2 binds to the voltage-dependent protein at the interface of the sensor and effector domains and mediates coupling between the two.

To summarize, VCF has shown that the KCNQ1 VSD is loosely coupled to the channel pore, and this interaction is critically dependent on interaction with PIP2. VSD-pore interaction is also modulated by KCNE1 to endow the slow kinetics of the native $\mathrm{I}_{\mathrm{Ks}}$ channel, and previous computer simulations have shown that these changes are critical in allowing $\mathrm{I}_{\mathrm{Ks}}$ regulation of AP duration at fast heart rates (Silva and Rudy, 2005). The new VCF data showing how VSD activation is connected to pore opening may serve to improve these models, as discussed above for Nav1.5 and Cav1.2. In particular, a significant effort has been made to create atomically detailed models of the $\mathrm{I}_{\mathrm{Ks}} \mathrm{VSD}$, with the aim of connecting its conformation to the dynamics of the AP (Nekouzadeh and Rudy, 2011; Silva and Rudy, 2010; Silva et al., 2009). We expect the VCF results described above to prove invaluable for verifying these models, allowing their VSD movement predictions to be experimentally tested. A key question that remains, and could be readily addressed with VCF, is how phosphorylation by protein kinase A (PKA) increases both the rate at which $\mathrm{I}_{\mathrm{Ks}}$ activates and its conductance, allowing $\mathrm{I}_{\mathrm{Ks}}$ to significantly determine AP repolarization in the presence of $\beta$-adrenergic stimulation.

\subsection{Rapid delayed rectifier $K^{+}$channel Kv11.1}

The pore-forming subunit of $\mathrm{I}_{\mathrm{Kr}}$ channels, Kv11.1, has also been studied by VCF, mainly to investigate the gating properties of hERG that allow it to return to the open state during the late phases of repolarization to determine AP duration.

The earliest VCF study on hERG (Smith and Yellen, 2002) acquired signals from three adjacent positions near the external end of S4, each of which reported a unique fluorescence signal. A slow fluorescence change observed with all three VCF constructs (E518C, E519C, and E520C) had kinetics that resembled hERG activation and deactivation, and the $\mathrm{F}-\mathrm{V}$ curve of one mutant closely matched the $\mathrm{G}-\mathrm{V}$ relationship. When deactivation was modulated by the $\mathrm{NH}_{2}-$ terminal deletion $\Delta 2-137$, the kinetics of the slow fluorescence component paralleled the kinetic changes of deactivation.

Based on these observations and the proximity of the reporter positions to the VSD, the authors suggested that the slow 
fluorescence change reported on S4 movements that underlie HERG activation gating rather than the opening and closing of the pore. The authors tried to correlate the fast component of fluorescence shown by E518C and E519C with the fast inactivation and recovery of the channel, and found a good match between the kinetics of the processes. However, the alterations of inactivation kinetics, either by TEA or by mutations, did not affect the fast fluorescence component, indicating a lack of a causal link between the two. The electrochromic effect, discussed above, was suspected to cause the extremely fast kinetics of the fast fluorescence decrease upon initial depolarization. However, because the fast fluorescence component had similar state dependence, nonlinearity, and voltage dependence to channel inactivation, it was suggested that this movement could also be connected to be a fast VSD movement linked to inactivation.

Thus, even though a direct correlation among the various fluorescence states and gating states of the VSD and the pore could not be established, the authors devised a model with two distinct, but coupled motions of the VSD that could reasonably recapitulate the observed fluorescence and current data (Fig. 6A). They concluded

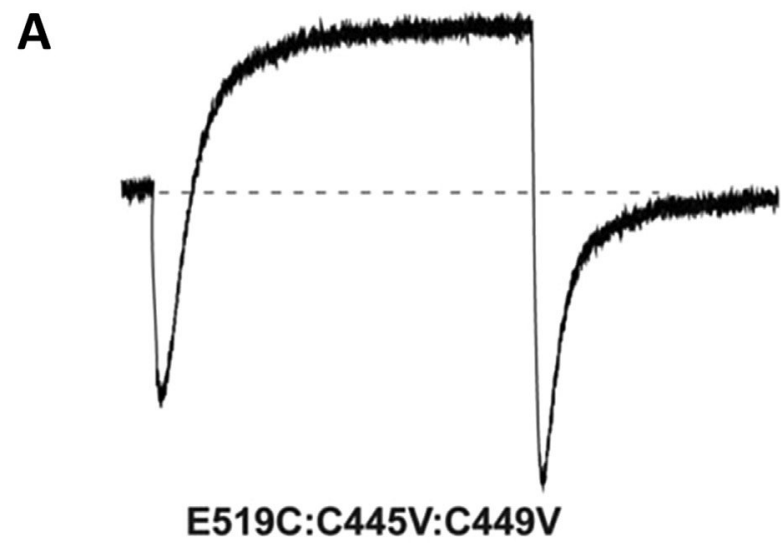

$$
500 \mathrm{~ms}
$$

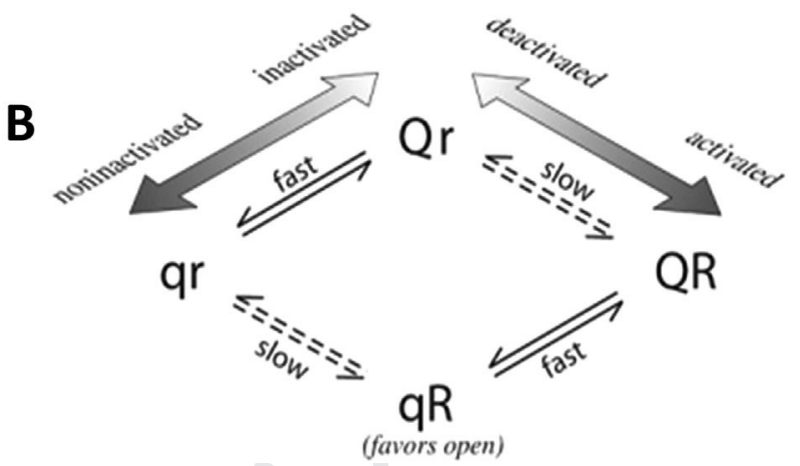

Fig. 6. A) A representative fluorescence signal recorded by Es-Salah-Lamoureux et al. from hERG E519C channels in the C445V:C449V background, which prevents the labeling and the consequent contamination of the VCF signal by two endogenous cysteines. The membrane was depolarized to $+40 \mathrm{mV}$ for $1 \mathrm{~s}$, from a holding potential of $-80 \mathrm{mV}$ and then returned to $-110 \mathrm{mV}$ (Es-Salah-Lamoureux et al., 2010). The signal obtained was qualitatively similar to that of Smith and Yellen, but was cleaner due to improved signal to noise ratio. B) Although Smith and Yellen could not establish a clear association between the fluorescence signals and gating transitions of the channel, they devised a model with four VSD states that reproduces the observed kinetics reasonably well. The two assumed conformational motions of the VSD are between the deactivated ( $\mathrm{r}$ ) and activated $(\mathrm{R})$ and the non-inactivated $(\mathrm{q})$ and inactivated $(\mathrm{Q})$ states, the former corresponding to the slow, the latter to the fast component of fluorescence (Smith and Yellen, 2002). that the unusually slow activation kinetics of hERG may be attributed to slow VSD movement, and suggest that fast VSD movements may be linked to inactivation. Later, the existence of two hERG VSD kinetic components was confirmed by gating current measurements that reflect the movement of $\mathrm{S} 4$ charges across the membrane electric field (Piper et al., 2003).

Further work showed that two endogenous cysteines in the S1-S2 linker distorted the signals reported by the S4-labeled positions (Es-Salah-Lamoureux et al., 2010). Removing these endogenous cysteines enabled cleaner measure of VSD activation. As in the previous two studies, upon depolarization, the fluorescence showed two kinetic components (Fig. 6B). However, in contrast to previous work, the authors attributed the fast component to a fast VSD movement and the slow component to a second conformational rearrangement of the protein also sensed by the reporter dye, which represents channel opening upon depolarization and channel closing at hyperpolarization. In an inactivation-removed channel, the initial fast component was still present, supporting the suggestion that the fast quenching step does not report on inactivation processes, but is instead caused by S4 movement.

The voltage dependence of the fluorescence change upon repolarization closely overlapped with that of channel closing, even in the inactivation-removed channel, and application of low $\mathrm{pH}$ accelerated ionic current deactivation and the decay of fluorescence tails by the same factor. These observations provided strong support for the idea that the fluorescence signal during repolarization describes pore closure during channel deactivation. Thus, contrary to previous models, this study proposed that VSD movement in hERG is not inherently slow; instead a secondary sequential slow rearrangement following quick VSD movement leads to pore opening, which is also detected by the dye in the vicinity of S4.

Additional processes may influence gating kinetics, such as the electromechanical coupling between the voltage sensing domain and the pore domain via the S4-S5 linker helix (Cheng and Claydon, 2012), which is less efficient in hERG than in Shaker (Van Slyke et al., 2012). To test this idea, (Thouta et al., 2014) used proline substitutions and observed VSD movement via VCF in trapped-open channels and concluded that voltage sensor movement is intrinsically slow in hERG channels.

While VCF results that probe the connection between the VSD and pore opening have been confusing, the method has proven useful for studying drug interaction. A recent study (Guo et al., 2015) used VCF along with other techniques to investigate the mechanism of action of a known hERG activator NS1643. As residue L529 in the S4 of hERG was previously shown to be close to the interaction site of NS1643 and mutation of the equivalent residue in Shaker to isoleucine had a strong effect on the cooperative motion of the VSDs, the L529I mutant was used to study the interaction. NS1643 was found to reduce the voltage sensitivity of VSD movement and slow the return of the VSD to its resting conformation upon repolarization. The authors suggested a direct effect on VSD transitions by NS1643. Their molecular dynamics results indicated that L529 is a key residue in determining the VSD local structure and that the L529I mutation introduced a kink in the S4 helix and consequently affected NS1643 binding by regulating the appropriate structure of the binding site. According to their model, binding of the hydrophobic NS1643 weakens the strength of a saltbridge that stabilizes the resting state of the VSD thereby promoting easier activation upon depolarization, which is then stabilized by direct interaction of the drug with another residue. Based on the experimental results, a kinetic model was devised, which indicated that NS1643 affects early gating transitions of the VSD that precede the opening of the activation gate (Perissinotti et al., 2015). Thus, this study illustrates how VCF data may be used to parameterize kinetic models. 
Although VCF experiments have provided some insight into the nature of hERG gating, a consensus model that relates the observed signals to channel gating remains elusive. Future studies that simultaneously perturb both the VSD and ionic current kinetics, perhaps with Long QT Type 2 linked mutations, may eventually allow resolution of these questions.

\section{5. $\mathrm{Na}+/ \mathrm{K}+$ ATPase}

In cardiac tissue, the $\mathrm{Na}^{+} / \mathrm{K}^{+}$ATPase plays an important role in maintaining the membrane potential and ion homeostasis. The enzyme is a member of P-type ATPase family, homologous to sarcoplasmic reticulum $\mathrm{Ca}^{2+}$-ATPase (SERCA) (Axelsen and Palmgren, 1998; Geering et al., 1989). During ATP hydrolysis, Ptype ATPases are phosphorylated at a highly conserved aspartate residue (Axelsen and Palmgren, 1998). $\mathrm{Na}^{+} / \mathrm{K}^{+}$ATPase is composed of two mandatory subunits, the $\alpha$ and $\beta$ subunits (Jorgensen and Pedersen, 2001). The $\alpha$ subunit contains 10 transmembrane segments, including $\mathrm{Na}^{+} / \mathrm{K}^{+}$ion binding domains, cytoplasmic phosphorylation sites, inhibitor (ouabain and digitoxin) and activator binding domain (Kaplan, 2002). The $\beta$ subunit is a single membrane spanning protein, which acts as chaperone to assure proper folding and expression of $\alpha$ subunits on the cell membrane (Béguin et al., 1998; Colonna et al., 1997), and it was also shown to modulate cation binding affinity to the $\alpha$ subunit (Jaisser et al., 1994). The $\alpha$ subunit has four isoforms, $\alpha 1$ through $\alpha 4$, while $\alpha 3$ is the most abundant isoform in heart (Schwinger et al., 2003; Zahler et al., 1996).

In cardiomyocytes, cardiac glycosides have been shown to bind to $\mathrm{Na}^{+} / \mathrm{K}^{+}$ATPase and cause a positive inotropic effect by inhibiting the enzyme's activity (Schwinger et al., 2003). This inhibition increases the intracellular $\mathrm{Na}^{+}$concentration, which reduces $\mathrm{Na}^{+} / \mathrm{Ca}^{+}$ exchanger driving force, leading to elevation of $\mathrm{Ca}^{2+}$ intracellular concentration during repolarization phase (Schwinger et al., 2003). In heart failure patients, the $\mathrm{Na}^{+} / \mathrm{K}^{+}$ATPase concentration is reduced by $\sim 40 \%$ (Schwinger et al., 2003). More specifically, expression of the $\alpha 1, \alpha 3$, and $\beta 1$ subunits have all been shown to be significantly reduced (Schwinger et al., 2003; Zahler et al., 1996). Cardiac glycosides, such as digoxin, have been regularly prescribed to patients with congenital heart failure (England, 1997) and atrial fibrillation (Falk et al., 1987).

The $\mathrm{Na}^{+} / \mathrm{K}^{+}$ATPase reaction cycle is described by the AlbersPost Scheme (Fig. 7A) (Albers, 1967; Post et al., 1972). The enzyme mainly transforms between two primary conformational states, E1 and E2. In the E1 state, the enzyme has ion binding sites facing the cytoplasm for $\mathrm{K}^{+}$releasing and $\mathrm{Na}^{+}$rebinding, while after phosphorylation, the enzyme switches to the E2 state, where the ion binding sites face extracellularly and the $\mathrm{Na}^{+}$ion passage is occluded. The helix M5 and the M5-M6 loop were shown to be important in the coupling between ATP hydrolysis and ion

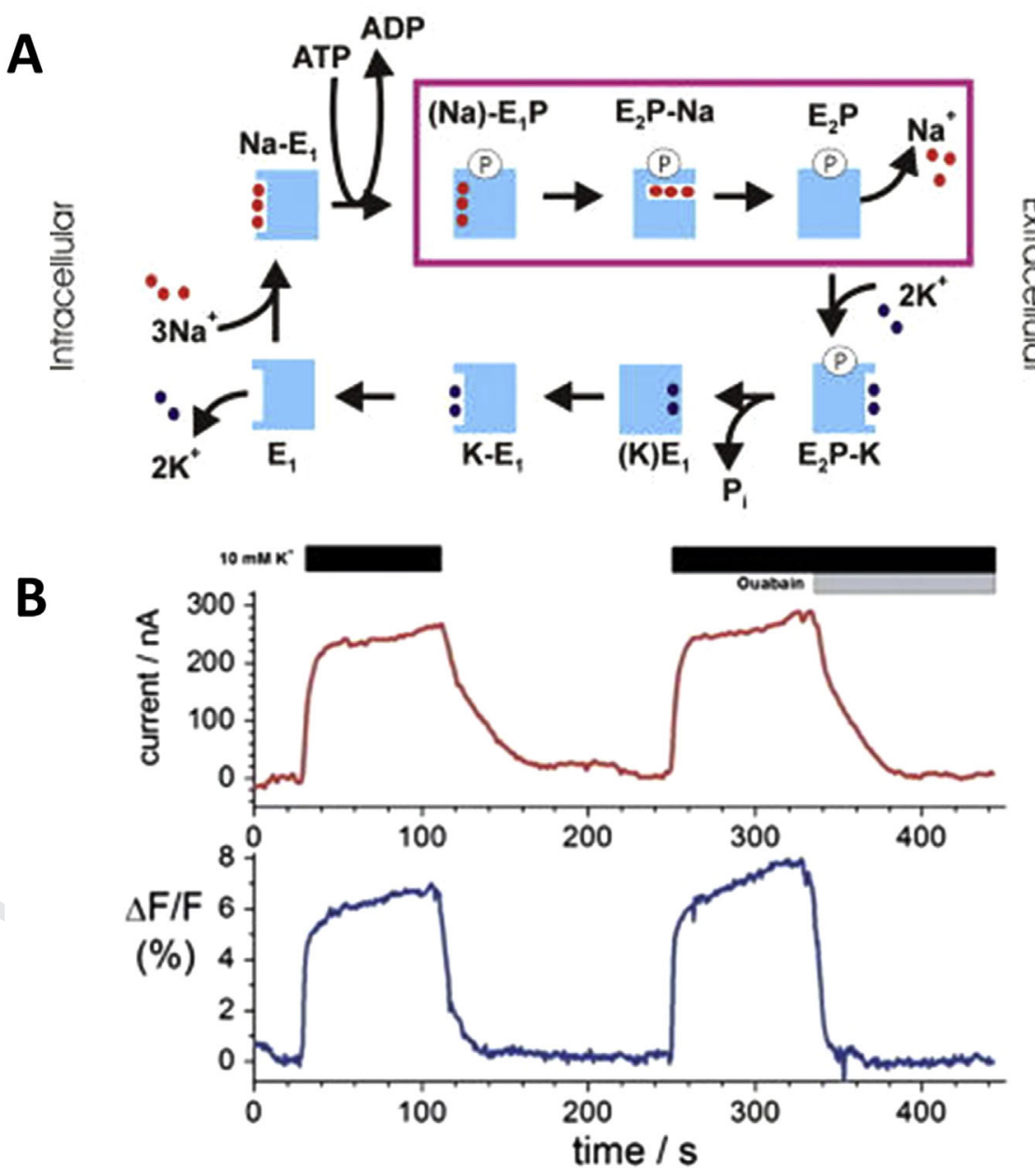

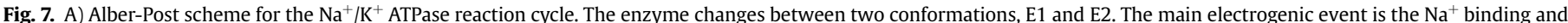

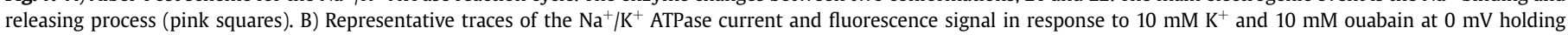
potential, recorded from Xenopus oocytes co-injected with the $\alpha$ and F64C $\beta$ subunits (Dempski et al., 2009, 2005). 
transport, during which they translocate by up to 5 A during $\mathrm{Na}^{+}$/ $\mathrm{K}^{+}$ATPase conformational rearrangement (Cha et al., 1999b; Glauner et al., 1999). Traditionally, conformational information is obtained by measuring transient pump currents under the $\mathrm{Na}^{+} / \mathrm{Na}^{+}$ exchange condition (Holmgren et al., 2000). However, this method provides limited information about the enzyme conformation under $\mathrm{Na}^{+} / \mathrm{K}^{+}$turnover conditions.

Recently, the Bamberg group employed VCF to study the $\mathrm{Na}^{+} / \mathrm{K}^{+}$ conformational dynamics and its subunits' interactions. Cysteine scanning mutagenesis on the M5-M6 loop of the sheep $\alpha 1$ subunit identified the N790C residue that, when tethered to fluorophore, can produce a fluorescent signal in response to transmembrane potential change and extracellular solution change (Geibel et al., 2003). Under $\mathrm{Na}^{+} / \mathrm{Na}^{+}$exchange conditions, dephosphorylation happens very slowly while the enzyme shuttles between the E1P and E2P transitions in response to the transmembrane voltage change, generating a transient current due to $\mathrm{Na}^{+}$release and rebinding (Geibel et al., 2003). The fluorescence signal under these conditions mimics transient current kinetics, and exclusively represents the E1P to E2P distribution. Using the fluorescence voltage relationship $(\mathrm{F}-\mathrm{V})$ of $\mathrm{N790C}$ under $\mathrm{Na}^{+} / \mathrm{Na}^{+}$exchange conditions for calibration, they continued investigating the $\left[\mathrm{K}^{+}\right]$dependence of fluorescence signals. The F-V curve shows the E1P and E2P states distribution, where high fluorescence represents an accumulation of the E1P conformation, and low fluorescence shows a buildup of the E2P state (Geibel et al., 2003). With increasing $\left[\mathrm{K}^{+}\right]$concentration, fluorescence had a higher stationary value at $-80 \mathrm{mV}$, suggesting an accumulation of the E1P state (Geibel et al., 2003). The fluorescence voltage relationship showed a positive shift in $V_{1 / 2}$ and a decrease in slope when the $\mathrm{K}^{+}$concentration was elevated, from which the authors concluded that the $\mathrm{K}^{+}$transport steps in the Alber-Post Cycle leads to an inward transport of positive charges that is less electrogenic than the $\mathrm{Na}^{+}$transport mode (Geibel et al., 2003).

Even though the N790C construct successfully reports fluorescence signals describing the $\mathrm{Na}^{+} / \mathrm{K}^{+}$pump conformational changes, this mutation alters the ion pump kinetics by causing a significant negative shift in the $\mathrm{V}_{1 / 2}$ of the E1P/E2P states distribution, and slows the transient $\mathrm{Na}^{+}$current kinetics under $\mathrm{Na}^{+} / \mathrm{Na}^{+}$exchange condition (Geibel et al., 2003). In 2005, Dempski et al. identified three residues on the $\mathrm{Na}^{+} / \mathrm{K}^{+}$pump $\beta$ subunit (S62C, F64C, and K65C) that, when coexpressed with the $\alpha$ subunit, exhibit fluorescence changes (Dempski et al., 2005). However, fluorescent signals from F64C $\beta$ show an additional slow component, and neither the fast nor slow components correlates with the pump E1/E2 conformational change. The $\mathrm{K} 65 \mathrm{C} \beta$ construct alters the transient $\mathrm{Na}^{+}$ current kinetics under $\mathrm{Na}^{+} / \mathrm{Na}^{+}$exchange condition, suggesting this charge neutralization mutation may affect the voltage dependence of cation binding and release to the pump. In contrast to N790C construct, S62C $\beta$ VCF construct does not alter the pump kinetics, suggesting that using fluorescence labeling of the $\beta$ subunit provides more physiologically relevant information on pump conformations under different ion transport modes (Fig. 7B) (Dempski et al., 2005).

The development of the VCF technique for the $\mathrm{Na}^{+} / \mathrm{K}^{+}$ATPase facilitated the study of post-translational modulations of the pump, such as glycosylation (Dürr et al., 2008), $\beta$ subunit binding (Dempski et al., 2006), and FXYD family of proteins interactions (Dempski et al., 2008). Despite the great advancement made in understanding the pump mechanisms, these VCF results have not been linked to the cardiac context. Further studies of the isoform $\alpha 3$ $\mathrm{Na}^{+} / \mathrm{K}^{+}$ATPase, and the cardiac glycosides' effects on the pump conformational dynamics, could be conducted using VCF.

From a computational view, the role of the $\mathrm{Na}^{+} / \mathrm{K}^{+}$ATPase is often overlooked, due to the slow nature of its effect on the AP, which is exerted by its control of the intracellular $\mathrm{Na}^{+}$concentration. However, in addition to the ATP-sensitive $\mathrm{K}^{+}$current (Nichols, 2006) and $\mathrm{I}_{\mathrm{Ks}}$ (Li et al., 2013), the $\mathrm{Na}^{+} / \mathrm{K}^{+}$ATPase provides one of a few connections to ATP concentration, a critical cell parameter that is altered during ischemia. Given the complex dependence of pump function on ionic concentration, $\mathrm{pH}$, membrane potential, and ATP/ ADP concentration, its contributions to myocyte physiology and pathophysiology during ischemia will not be easily inferred. Thus, the results described above could significantly improve mechanistic models of the $\mathrm{Na}^{+} / \mathrm{K}^{+}$ATPase (Oka et al., 2010), and improve our understanding of its role in determining the electrophysiology under nominal and ischemic conditions.

\section{Emerging methods}

While VCF in its current form has produced many exciting results and many more are on the horizon, several limitations remain. Some of these may be resolved and new information may be gained by using emerging methods such as patch clamp fluorometry, fluorescent un-natural amino acids, and VCF-based distance measurements, which we will discuss in this section.

\subsection{Patch-clamp fluorometry}

Patch-clamp fluorometry (PCF) adapts the VCF principles of measuring conformational changes by disulfide conjugated fluorophore quenching to excised patches (Zheng and Zagotta, 2000), allowing higher sensitivity and time resolution for recordings (Zheng and Zagotta, 2003). PCF typically utilizes the inside-out patch configuration, which allows fluorophore access to intracellular sites and the use of anionic and cationic quenchers to monitor the movement of charged residues. Additionally, excising the patch from the cell removes auto-fluorescence produced by the intracellular milieu. PCF can also be performed in combination with Förster resonance energy transfer (FRET), which has 1-10 nm spatial resolution, to gain additional mechanistic insight (Harms et al., 2003; Miranda et al., 2012; Zheng and Zagotta, 2003). For most PCF experiments, an inverted epifluorescence microscope with a high numerical aperture (NA) objective is utilized to focus on a patch membrane. Due to their responsiveness to small signals, photomultiplier tube (PMTs) and charge-coupled device (CCD) camera are used for signal detection (Zheng and Zagotta, 2003, 2000; Zheng, 2006). PCF has been successfully applied in various studies of ion channels, such as understanding conformational changes of cyclic nucleotide-gated (CNG) channels upon cyclicnucleotide or $\mathrm{Ca}^{2+}$-Camodulin binding (Trudeau and Zagotta, 2004), and voltage $/ \mathrm{Ca}^{2+}$ dependent conformational changes in BK channels (Miranda et al., 2012). However, PCF is a technically challenging method, and still has not been widely applied.

\subsection{Fluorescent un-natural amino acids (fUAA)}

Un-natural amino acids (UAA) have been recently incorporated into channels in heterologous expression systems (Beene et al., 2003; Kalstrup and Blunck, 2013a). The general approach to incorporating UAA into eukaryotic cells is the nonsense suppression method, where an amber (TAG) codon is introduced to site of interest (Liu et al., 2007; Noren et al., 1989). tRNA that is compatible with UAA is introduced and directed by a proper anticodon to the TAG site, where the UAA will be incorporated into polypeptide by the ribosome (Liu et al., 2007; Noren et al., 1989). Due to the nature of the incorporation method, the UAA can be inserted at any location on the protein. Two incorporation methods have been applied in studies of membrane receptors and ion channels (Pless and Ahern, 2013). The first approach can be conducted in various 
expression systems, including bacteria, mammalian cell types, and other native cells. Suppressor tRNA, aminoacyl synthetase (aaRS), and the gene of interest with a TAG mutation are co-transfected into cells, allowing each cell to synthesize the required proteins (Pless and Ahern, 2013). The second approach requires co-injection of mRNA containing a TAG codon, and tRNA that contains UAA conjugated in vitro (Pless and Ahern, 2013). This method is limited to the Xenopus oocyte expression system. However, when incorporating UAA, especially at locations close to the $\mathrm{N}$-terminus of the protein, expression homogeneity of the protein needs to be carefully examined, since leak expression have been observed, due to the reinitiation at non-canonical start codon, or stop codon readthrough (Kalstrup and Blunck, 2015).

Recently, fluorescent un-natural amino acids (fUAA) have been developed, such as 6-propionyl-2-(N,N-,dimethyl)-amino-napthelene (Anap), which is highly sensitive to its environment, and has a size similar to tryptophan (Chatterjee et al., 2013). The advantage of the fUAA approach over traditional methods is that the protein is labeled much more specifically, removing background cysteine labeling, and a much smaller fluorophore size (Chatterjee et al., 2013). Anap has been used to probe the Shaker potassium channel, as an alternative method to VCF (Kalstrup and Blunck, 2013b). In these studies, Anap was incorporated into three locations: A359 at top of the S4, V234 at the bottom of S1, and H486 at the C-terminal S6 (Kalstrup and Blunck, 2013b). Tracking H486 revealed that Shaker channel pore opening occurs in two steps, as its fluorescence voltage relationship ( $\mathrm{F}-\mathrm{V}$ curve) contains two components (Kalstrup and Blunck, 2013b). The first component resides between QV (gating charge-voltage) and GV (conductance-voltage) curve, indicating that this first C-terminal S6 movement is a cooperative event of all four subunits, while it is not sufficient to open the pore (Kalstrup and Blunck, 2013b). The second component coincides with the GV, suggesting the second transition leads to pore opening (Kalstrup and Blunck, 2013b). While these initial results are promising, it remains to be seen whether this approach can be extended to channels that do not express at the extremely high levels of Shaker.

\subsection{Distance measurement by tryptophan-induced quenching}

One question that persists in VCF studies is that of the distance between the tracked protein segment and the rest of the channel. Mansoor et al. developed the tryptophan-induced quenching of fluorophore method to study the proximity of amino acids pairs within a protein or protein-protein interactions (Mansoor et al., 2010, 2002). Initially, they investigated bimane fluorescence quenching by tryptophan residue in T4 lysozyme (Mansoor et al., 2002). They showed that tryptophan can reduce the Bimane fluorescence intensity by up to $80 \%$ when within the proximity of van der Waals contact distance (5-15 $\AA$ ), and this quenching effect is highly dependent on distance and orientation (Mansoor et al., 2002). When the tryptophan residue is mutated to phenylalanine, the phenomenon no longer persists (Mansoor et al., 2002). This technique was then applied to study conformational switches of Gprotein coupled receptors (GPCRs), including rhodopsin and beta2adrenoceptor ( $\beta 2-A R$ ) (Yao et al., 2006). In 2010, Mansoor et al. further studied multiple fluorophores that can be used in tryptophan-induced quenching. Different fluorophores exhibit distinct quenching profiles of intensity reduction and fluorescence lifetime reduction, which correlate with fluorophore size, rotational flexibility, and the length of the attachment linker (Mansoor et al., 2010).

Recently, Pantazis and Olcese applied this technique to probe rearrangement of BK channel transmembrane segments during gating (Pantazis and Olcese, 2012). The BK channel has non- canonical voltage sensing mechanisms compared to other voltage-gated channels. It has an additional transmembrane segment S0, and besides S4, the S2-S3 segments of the channel also carry charge across the transmembrane field (Meera et al., 1997; Wallner et al., 1996). When a MTS-TAMRA/TMRM fluorophore is conjugated to the top of S1 or S2, the fluorescence is increased during gating. However, when the tryptophan residue W203 resides on top of S4 is mutated to valine, the fluorescence change is significantly reduced, suggesting that the increase of fluorescence was induced by W203 moving away from the fluorophore (Pantazis and Olcese, 2012). This result shows that S4 diverges from S1 and S4 during channel activation. By introducing the MTS-TAMRA fluorophore on top of S1 and a tryptophan on different locations of the S1-S2 linker, they observed quenching of the fluorophore by the introduced tryptophan, indicating S1 and S2 segments move closer during activation (Pantazis and Olcese, 2012).

\section{Concluding remarks}

For many years, cardiac AP models have promised to identify novel anti-arrhythmic targets, based on an improved understanding of the nonlinear interactions between the molecules that generate the action potential. However, this promise has remained unfulfilled, in large part because the kinetic transitions that define these models remain unconnected to the molecular movements within channels and transporters that determine their function. VCF provides a means to directly quantify the kinetics of these molecular movements.

Many decades of anti-arrhythmic drug development have shown that the most effective agents interact with multiple channels to control the AP. A prime example is the widely-prescribed amiodarone, which blocks $\mathrm{I}_{\mathrm{Na}}, \mathrm{I}_{\mathrm{Ca}, \mathrm{L}}$ and $\mathrm{I}_{\mathrm{Kr}}$ (Sun et al., 1999). The relative success of this molecule in comparison to more specific channel blockers suggests that a combination of targets will prove to be more effective than a modulation of a single molecule. The development of VCF-parameterized models for each of the major ionic currents has the potential to define sets of conformations that could be targeted simultaneously. Moreover, it is unlikely that such sets would be intuitively predicted.

In conclusion, while VCF was first developed nearly 20 years ago, it is only now being applied to unmask the molecular movements that fundamentally determine the dynamics of the cardiac action potential. We expect that this connection will eventually lead to not only to a deeper understanding of cardiac myocyte excitation, but also to vastly improved anti-arrhythmic therapies.

\section{Funding sources}

Burroughs Wellcome Fund Career Award at the Scientific Interface 1010299.

(J.R.S.); American Heart Association fellowship 15PRE25080073 (W.Z.); KTIA_NAP_13-2-2015-0009 (Z.V.) and Z.V. is Bolyai Fellowship awardee. This work was supported in part by the TÁMOP-4.2.2.D-15/1/KONV-2015-0016 project implemented through the New Széchenyi Plan co-financed by the European Social Fund (Z.V.).

\section{Conflict of interest disclosures}

None.

\section{Acknowledgments}

We thank James Ballard for many helpful discussions and advice. 


\section{Q3 Uncited reference}

Albert et al., 1999.

\section{References}

Abbott, G.W., Sesti, F., Splawski, I., Buck, M.E., Lehmann, M.H., Timothy, K.W. Keating, M.T., Goldstein, S.A., 1999. MiRP1 forms IKr potassium channels with HERG and is associated with cardiac arrhythmia. Cell 97, 175-187. http:// dx.doi.org/10.1016/S0092-8674(00)80728-X.

Abriel, H., 2007. Roles and regulation of the cardiac sodium channel Na v 1.5: recent insights from experimental studies. Cardiovasc. Res. 76, 381-389. http:// dx.doi.org/10.1016/j.cardiores.2007.07.019.

Aggarwal, S.K., MacKinnon, R., 1996. Contribution of the S4 segment to gating charge in the Shaker K+ channel. Neuron 16, 1169-1177. http://dx.doi.org/ 10.1016/S0896-6273(00)80143-9.

Albers, R.W., 1967. Biochemical aspects of active transport. Annu. Rev. Biochem. 36 727-756. http://dx.doi.org/10.1146/annurev.bi.36.070167.003455.

Albert, C., Ruben, P.C., George, A.L., Fujimoto, E., Bezanilla, F., 1999. Voltage sensors in domains III and IV, but not I and II, are immobilized by $\mathrm{Na}+$ channel fas inactivation. Neuron 22, 73-87. http://dx.doi.org/10.1016/S0896-6273(00) 80680-7.

Arcisio-Miranda, M., Muroi, Y., Chowdhury, S., Chanda, B., 2010. Molecular mechanism of allosteric modification of voltage-dependent sodium channels by local anesthetics. J. Gen. Physiol. 136, 541-554. http://dx.doi.org/10.1085/ jgp.201010438.

Axelsen, K.B., Palmgren, M.G., 1998. Evolution of substrate specificities in the P-type ATPase superfamily. J. Mol. Evol. 46, 84-101. http://dx.doi.org/10.1007 PL00006286.

Barhanin, J., Lesage, F., Guillemare, E., Fink, M., Lazdunski, M., Romey, G., 1996. K(V) LQT1 and lsK (minK) proteins associate to form the I(Ks) cardiac potassium current. Nature 384, 78-80. http://dx.doi.org/10.1038/384078a0.

Barro-Soria, R., Rebolledo, S., Liin, S.I., Perez, M.E., Sampson, K.J., Kass, R.S. Larsson, H.P., 2014. KCNE1 divides the voltage sensor movement in KCNQ1/ KCNE1 channels into two steps. Nat. Commun. 5, 3750. http://dx.doi.org $10.1038 /$ ncomms4750.

Beene, D.L., Dougherty, D.A., Lester, H.A., 2003. Unnatural amino acid mutagenesis in mapping ion channel function. Curr. Opin. Neurobiol. http://dx.doi.org 10.1016/S0959-4388(03)00068-0.

Béguin, P., Hasler, U., Beggah, A., Horisberger, J.D., Geering, K., 1998. Membrane integration of $\mathrm{Na}, \mathrm{K}-\mathrm{ATPa} e$ alpha-subunits and beta-subunit assembly. J. Biol. Chem. 273, 24921-24931.

Ben-Johny, M., Yang, P.S., Niu, J., Yang, W., Joshi-Mukherjee, R., Yue, D.T., 2014. Conservation of $\mathrm{Ca} 2+/$ calmodulin regulation across $\mathrm{Na}$ and $\mathrm{Ca} 2+$ channels. Cell 157, 1657-1670. http://dx.doi.org/10.1016/j.cell.2014.04.035.

Benson, D.W., Wang, D.W., Dyment, M., Knilans, T.K., Fish, F.A., Strieper, M.J. Rhodes, T.H., George, A.L., 2003. Congenital sick sinus syndrome caused by recessive mutations in the cardiac sodium channel gene (SCN5A). J. Clin. Invest 112, 1019-1028. http://dx.doi.org/10.1172/JCI18062.

Bezanilla, F., 2008. How membrane proteins sense voltage. Nat. Rev. Mol. Cell Biol. 9 323-332. http://dx.doi.org/10.1038/nrm2376.

Bianchi, L., Shen, Z., Dennis, a T., Priori, S.G., Napolitano, C., Ronchetti, E., Bryskin, R., Schwartz, P.J., Brown, a M., 1999. Cellular dysfunction of LQT5-minK mutants: abnormalities of IKs, IKr and trafficking in long QT syndrome. Hum. Mol. Genet. 8, 1499-1507. http://dx.doi.org/10.1093/hmg/8.8.1499.

Blunck, R., 2015. Investigation of ion channel structure using fluorescence spectroscopy. In: Zheng, J., Trudeau, M.C. (Eds.), Handbook of Ion Channels. CRC Press, pp. 113-133. http://dx.doi.org/10.1201/b18027-12.

Blunck, R., Starace, D.M., Correa, A.M., Bezanilla, F., 2004. Detecting rearrangements of shaker and $\mathrm{NaChBac}$ in real-time with fluorescence spectroscopy in patchclamped mammalian cells. Biophys. J. 86, 3966-3980. http://dx.doi.org 10.1529/biophysj.103.034512.

Bock, J., Szabó, I., Gamper, N., Adams, C., Gulbins, E., 2003. Ceramide inhibits the potassium channel Kv1.3 by the formation of membrane platforms. Biochem. Biophys. Res. Commun. 305, 890-897. http://dx.doi.org/10.1016/S0006 291X(03)00763-0.

Bodi, I., Mikala, G., Koch, S.E., Akhter, S.A., Schwartz, A., 2005. The L-type calcium channel in the heart: the beat goes on. J. Clin. Invest. http://dx.doi.org/10.1172/ JCI27167.

Brugada, P., Brugada, J., 1992. Right bundle branch block, persistent ST segment elevation and sudden cardiac death: a distinct clinical and electrocardiographic syndrome. A multicenter report. J. Am. Coll. Cardiol. 20, 1391-1396 doi:07351097(92)90253-J [pii].

Campos, F.V., Chanda, B., Beirão, P.S.L., Bezanilla, F., 2008. Alpha-scorpion toxin impairs a conformational change that leads to fast inactivation of muscle sodium channels. J. Gen. Physiol. 132, 251-263. http://dx.doi.org/10.1085/ jgp. 200809995.

Campos, F.V., Chanda, B., Beirão, P.S.L., Bezanilla, F., 2007. beta-Scorpion toxin modifies gating transitions in all four voltage sensors of the sodium channel. J. Gen. Physiol. 130, 257-268. http://dx.doi.org/10.1085/jgp.200609719.

Capes, D.L., Goldschen-Ohm, M.P., Arcisio-Miranda, M., Bezanilla, F., Chanda, B., 2013. Domain IV voltage-sensor movement is both sufficient and rate limiting for fast inactivation in sodium channels. J. Gen. Physiol. 142, 101-112. http: dx.doi.org/10.1085/jgp.201310998.

Catterall, W.A., 2011. Voltage-gated calcium channels. Cold Spring Harb. Perspect. Biol. 3, 1-23. http://dx.doi.org/10.1101/cshperspect.a003947.

Cha, a, Bezanilla, F., 1997. Characterizing voltage-dependent conformational changes in the Shaker K+ channel with fluorescence. Neuron 19, 1127-1140. http://dx doi.org/101016/S0896-6273(00)80403-1.

Cha, A., Ruben, P.C., George, A.L., Fujimoto, E., Bezanilla, F., 1999a. Voltage sensors in domains III and IV, but not I and II, are immobilized by $\mathrm{Na}+$ channel fast inactivation. Neuron 22, 73-87. http://dx.doi.org/10.1016/S0896-6273(00) 80680-7.

Cha, A., Snyder, G.E., Selvin, P.R., Bezanilla, F., 1999b. Atomic scale movement of the voltage-sensing region in a potassium channel measured via spectroscopy. Nature 402, 809-813, http://dx doi.org/10.1038/45552.

Chakrapani, S., Sompornpisut, P., Intharathep, P., Roux, B., Perozo, E., 2010. The activated state of a sodium channel voltage sensor in a membrane environment. Proc. Natl. Acad. Sci. U. S. A. 107, 5435-5440. http://dx.doi.org/10.1073/ pnas.0914109107.

Chatterjee, A., Guo, J., Lee, H.S., Schultz, P.G., 2013. A genetically encoded fluorescent probe in mammalian cells. J. Am. Chem. Soc. 135, 12540-12543. http:// dx.doi.org/10.1021/ja4059553.

Chen, H., Ahsan, S.S., Santiago-Berrios, M.B., Abruña, H.D., Webb, W.W., 2010. Mechanisms of quenching of alexa fluorophores by natural amino acids. J. Am. Chem. Soc. 132, 7244-7245. http://dx.doi.org/10.1021/ja100500k.

Chen, L.Y., Ballew, J.D., Herron, K.J., Rodeheffer, R.J., Olson, T.M., 2007. A common polymorphism in SCN5A is associated with lone atrial fibrillation. Clin. Pharmacol. Ther. 81, 35-41. http://dx.doi.org/10.1038/sj.clpt.6100016.

Cheng, Y.M., Claydon, T.W., 2012. Voltage-dependent gating of hERG potassium channels. Front. Pharmacol. http://dx.doi.org/10.3389/fphar.2012.00083, 3 MAY.

Colonna, T.E., Huynh, L., Fambrough, D.M., 1997. Subunit interactions in the Na,KATPase explored with the yeast two-hybrid system. J. Biol. Chem. 272 , 12366-12372. http://dx.doi.org/10.1074/jbc.272.19.12366.

Combs, D.J., Shin, H.-G., Xu, Y., Ramu, Y., Lu, Z., 2013. Tuning voltage-gated channel activity and cellular excitability with a sphingomyelinase. J. Gen. Physiol. 142, 367-380. http://dx doi.org/10.1085/jgp.201310986.

Curran, M.E., Splawski, I., Timothy, K.W., Vincent, G.M., Green, E.D., Keating, M.T., 1995. A molecular basis for cardiac arrhythmia: HERG mutations cause long QT syndrome. Cell 80, 795-803. http://dx.doi.org/10.1016/0092-8674(95)90358-5.

Darbar, D., Kannankeril, P.J., Donahue, B.S., Kucera, G., Stubblefield, T., Haines, J.L., George, A.L., Roden, D.M., 2008. Cardiac sodium channel (SCN5A) variants associated with atrial fibrillation. Circulation 117, 1927-1935. http://dx.doi.org/ 10.1161/CIRCULATIONAHA.107.757955.

Davies, A., Hendrich, J., Van Minh, A.T., Wratten, J., Douglas, L., Dolphin, A.C., 2007. Functional biology of the $\alpha 2 \delta$ subunits of voltage-gated calcium channels. Trends Pharmacol. Sci. http://dx.doi.org/10.1016/j.tips.2007.03.005.

Decker, K.F., Heijman, J., Silva, J.R., Hund, T.J., Rudy, Y., 2009. Properties and ionic mechanisms of action potential adaptation, restitution, and accommodation in canine epicardium. Am. J. Physiol. Heart Circ. Physiol. 296, H1017-H1026. http://dx.doi.org/10.1152/ajpheart.01216.2008.

Dempski, R.E., Friedrich, T., Bamberg, E., 2009. Voltage clamp fluorometry: combining fluorescence and electrophysiological methods to examine the structure-function of the $\mathrm{Na}+/ \mathrm{K}+-$ ATPase. Biochim. Biophys. Acta - Bioenerg. http://dx.doi.org/10.1016/j.bbabio.2009.03.021.

Dempski, R.E., Friedrich, T., Bamberg, E., 2005. The beta subunit of the $\mathrm{Na}+/ \mathrm{K}+-$ ATPase follows the conformational state of the holoenzyme. J. Gen. Physiol. 125, 505-520. http://dx.doi.org/10.1085/jgp.200409186.

Dempski, R.E., Hartung, K., Friedrich, T., Bamberg, E., 2006. Fluorometric measurements of intermolecular distances between the $\alpha$ - and $\beta$-subunits of the $\mathrm{Na}+1$ K+-ATPase. J. Biol. Chem. 281, 36338-36346. http://dx.doi.org/10.1074/ jbc.M604788200.

Dempski, R.E., Lustig, J., Friedrich, T., Bamberg, E., 2008. Structural arrangement and conformational dynamics of the gamma subunit of the $\mathrm{Na}+/ \mathrm{K}+$-ATPase. Biochemistry 47, 257-266. http://dx doi.org/101021/bi701799b.

Doose, S., Neuweiler, H., Sauer, M., 2009. Fluorescence quenching by photoinduced electron transfer: a reporter for conformational dynamics of macromolecules. ChemPhysChem 10, 1389-1398, http://dx doi.org/101002/cphc 200900238.

Doose, S., Neuweiler, H., Sauer, M., 2005. A close look at fluorescence quenching of organic dyes by tryptophan. Chemphyschem 6, 2277-2285. http://dx.doi.org/ 10.1002/cphc.200500191.

Dürr, K.L., Tavraz, N.N., Zimmermann, D., Bamberg, E., Friedrich, T., 2008. Characterization of Na,K-ATPASE and H,K-ATPase enzymes with glycosylationdeficient $\beta$-subunit variants by voltage-clamp fluorometry in xenopus oocytes. Biochemistry 47, 4288-4297. http://dx.doi.org/10.1021/bi800092k.

England, T.N., 1997. The effect of digoxin on mortality and morbidity in patients with heart failure. N. Engl. J. Med. 336, 525-533. http://dx.doi.org/10.1056/ NEJM199702203360801.

Es-Salah-Lamoureux, Z., Fougere, R., Xiong, P.Y., Robertson, G.A., Fedida, D., 2010. Fluorescence-tracking of activation gating in human ERG channels reveals rapid S4 movement and slow pore opening. PLoS One 5. http://dx.doi.org/10.1371/ journal.pone.0010876.

Faber, G.M., Silva, J., Livshitz, L., Rudy, Y., 2007. Kinetic properties of the cardiac Ltype Ca2+ channel and its role in myocyte electrophysiology: a theoretical investigation. Biophys. J. 92, 1522-1543. http://dx.doi.org/10.1529/ biophysj.106.088807.

Falk, R.H., Knowlton, A.A., Bernard, S.A., Gotlieb, N.E., Battinelli, N.J., 1987. Digoxin for converting recent-onset atrial fibrillation to sinus rhythm. A randomized, 
double-blinded trial. Ann. Intern. Med. 106, 503-506. http://dx.doi.org/10.1016/ S0196-0644(87)80495-X.

Gandhi, C.S., Olcese, R., 2008. The voltage-clamp fluorometry technique. Methods Mol. Biol. 491, 213-231. http://dx.doi.org/10.1007/978-1-59745-526-8-17.

Ganetzky, B., Robertson, G a, Wilson, G.F., Trudeau, M.C., Titus, S. a, 1999. The eag family of $\mathrm{K}+$ channels in Drosophila and mammals. Ann. N. Y. Acad. Sci. 868, 356-369. http://dx.doi.org/10.1111/j.1749-6632.1999.tb11297.x.

Geering, K., Theulaz, I., Verrey, F., Häuptle, M.T., Rossier, B.C., 1989. A role for the beta-subunit in the expression of functional $\mathrm{Na}+-\mathrm{K}+-$ ATPase in Xenopus oocytes. Am. J. Physiol. 257, C851-C858.

Geibel, S., Kaplan, J.H., Bamberg, E., Friedrich, T., 2003. Conformational dynamics of the $\mathrm{Na}+/ \mathrm{K}+-$-ATPase probed by voltage clamp fluorometry. Proc. Natl. Acad. Sci. U. S. A. 100, 964-969. http://dx.doi.org/10.1073/pnas.0337336100.

Gellens, M.E., George, A.L., Chen, L.Q., Chahine, M., Horn, R., Barchi, R.L., Kallen, R.G., 1992. Primary structure and functional expression of the human cardiac tetrodotoxin-insensitive voltage-dependent sodium channel. Proc. Natl. Acad. Sci. U. S. A. 89, 554-558. http://dx.doi.org/10.1073/pnas.89.2.554.

Glauner, K.S., Mannuzzu, L.M., Gandhi, C.S., Isacoff, E.Y., 1999. Spectroscopic mapping of voltage sensor movement in the Shaker potassium channel. Nature 402, 813-817. http://dx.doi.org/10.1038/45561.

Guo, J., Cheng, Y.M., Lees-Miller, J.P., Perissinotti, L.L., Claydon, T.W., Hull, C.M., Thouta, S., Roach, D.E., Durdagi, S., Noskov, S.Y., Duff, H.J., 2015. NS1643 interacts around L529 of hERG to alter voltage sensor movement on the path to activation. Biophys. J. 108, 1400-1413. http://dx.doi.org/10.1016/j.bpj.2014.12.055.

Harms, G.S., Orr, G., Montal, M., Thrall, B.D., Colson, S.D., Lu, H.P., 2003. Probing conformational changes of gramicidin ion channels by single-molecule patchclamp fluorescence microscopy. Biophys. J. 85, 1826-1838. http://dx.doi.org/ 10.1016/S0006-3495(03)74611-6.

Heist, E.K., Ruskin, J.N., 2010. Drug-induced arrhythmia. Circulation 122, 1426-1435. http://dx.doi.org/10.1161/CIRCULATIONAHA.109.894725.

Hidalgo, P., Neely, A., 2007. Multiplicity of protein interactions and functions of the voltage-gated calcium channel??-subunit. Cell Calcium 42, 389-396. http:// dx.doi.org/10.1016/j.ceca.2007.05.009.

Hille, B., 2001. Ion channel excitable membranes. In: Sunderland Massachusetts USA, pp. 1-37. http://dx.doi.org/10.1007/3-540-29623-9_5640.

Hofmann, F., Flockerzi, V., Kahl, S., Wegener, J.W., 2014. L-type CaV1.2 calcium channels: from in vitro findings to in vivo function. Physiol. Rev. 94, 303-326. http://dx.doi.org/10.1152/physrev.00016.2013.

Holmgren, M., Wagg, J., Bezanilla, F., Rakowski, R.F., De Weer, P., Gadsby, D.C., 2000. Three distinct and sequential steps in the release of sodium ions by the $\mathrm{Na}+1$ K+-ATPase. Nature 403, 898-901. http://dx.doi.org/10.1038/35002599.

Hondeghem, L.M., Katzung, B.G., 1984. Antiarrhythmic agents: the modulated receptor mechanism of action of sodium and calcium channel-blocking drugs. Annu. Rev. Pharmacol. Toxicol. 24, 387-423. http://dx.doi.org/10.1146/ annurev.pa.24.040184.002131.

Hughes, L.D., Rawle, R.J., Boxer, S.G., 2014. Choose your label wisely: water-soluble fluorophores often interact with lipid bilayers. PLoS One 9, e87649. http:// dx.doi.org/10.1371/journal.pone.0087649.

Hund, T.J., Mohler, P.J., 2014. Role of CaMKII in cardiac arrhythmias. Trends Cardiovasc. Med. 25, 392-397. http://dx.doi.org/10.1016/j.tcm.2014.12.001.

Imredy, J.P., Yue, D.T., 1994. Mechanism of $\mathrm{Ca}(2+)$-sensitive inactivation of L-type Ca2+ channels. Neuron 12, 1301-1318. http://dx.doi.org/10.1016/08966273(94)90446-4

Islas, L.D., Zagotta, W.N., 2006. Short-range molecular rearrangements in ion channels detected by tryptophan quenching of bimane fluorescence. J. Gen. Physiol. 128, 337-346. http://dx.doi.org/10.1085/jgp.200609556.

Itoh, T., Tanaka, T., Nagai, R., Kikuchi, K., Ogawa, S., Okada, S., Yamagata, S., Yano, K., Yazaki, Y., Nakamura, Y., 1998. Genomic organization and mutational analysis of KVLQT1, a gene responsible for familial long QT syndrome. Hum. Genet. 103, 290-294.

Jaisser, F., Jaunin, P., Geering, K., Rossier, B.C., Horisberger, J.D., 1994. Modulation of the Na,K-pump function by beta subunit isoforms. J. Gen. Physiol. 103, 605-623. http://dx.doi.org/10.1085/jgp.103.4.605.

Jorgensen, P.L., Pedersen, P.A., 2001. Structure-function relationships of $\mathrm{Na}(+), \mathrm{K}(+)$, ATP, or $\mathrm{Mg}(2+)$ binding and energy transduction in Na,K-ATPase. Biochim. Biophys. Acta 1505, 57-74. http://dx.doi.org/10.1016/S0005-2728(00)00277-2.

Kalstrup, T., Blunck, R., 2015. Reinitiation at non-canonical start codons leads to leak expression when incorporating unnatural amino acids. Sci. Rep. 5, 11866. http:// dx.doi.org/10.1038/srep11866.

Kalstrup, T., Blunck, R., 2013a. Dynamics of internal pore opening in K(V) channels probed by a fluorescent unnatural amino acid. Proc. Natl. Acad. Sci. U. S. A. 110, 8272-8277. http://dx.doi.org/10.1073/pnas.1220398110.

Kalstrup, T., Blunck, R., 2013b. Dynamics of internal pore opening in K V channels probed by a fluorescent unnatural amino acid, 2013, pp. 3-8 doi:10.1073/ pnas.1220398110/-/DCSupplemental.www.pnas.org/cgi/doi/10.1073/ pnas.1220398110.

Kaplan, J.H., 2002. Biochemistry of Na,K-ATPase. Annu. Rev. Biochem 71, 511-535. http://dx.doi.org/10.1146/annurev.biochem.71.102201.141218.

Klymchenko, A.S., Demchenko, A.P., 2002. Electrochromic modulation of excitedstate intramolecular proton transfer: the new principle in design of fluorescence sensors. J. Am. Chem. Soc. 124, 12372-12379. http://dx.doi.org/10.1021/ ja027669l.

Kruse, M., Hammond, G.R.V., Hille, B., 2012. Regulation of voltage-gated potassium channels by PI(4,5)P2. J. Gen. Physiol. 140, 189-205. http://dx.doi.org/10.1085/ jgp.201210806.
Lakowicz, J.R., 2006. Mechanisms and dynamics of fluorescence quenching. Princ Fluoresc. 331-351. http://dx.doi.org/10.1007/978-0-387-46312-4_9.

Li, Y., Gao, J., Lu, Z., McFarland, K., Shi, J., Bock, K., Cohen, I.S., Cui, J., 2013. Intracellular ATP binding is required to activate the slowly activating $\mathrm{K}+$ channe I(Ks). Proc. Natl. Acad. Sci. U. S. A. 110, 18922-18927. http://dx.doi.org/10.1073/ pnas.1315649110.

Liman, E.R., Hess, P., Weaver, F., Koren, G., 1991. Voltage-sensing residues in the S4 region of a mammalian $\mathrm{K}+$ channel. Nature $353,752-756$. http://dx.doi.org/ $10.1038 / 353752 \mathrm{a} 0$.

Liu, W., Brock, A., Chen, S., Chen, S., Schultz, P.G., 2007. Genetic incorporation of unnatural amino acids into proteins in mammalian cells. Nat. Methods 4 239-244. http://dx.doi.org/10.1038/nmeth1016.

Long, S.B., Campbell, E.B., MacKinnon, R., 2005. Crystal structure of a mammalian voltage-dependent Shaker family K+ channel. Sci. (80-. ) 309, 897-903. http:/| dx.doi.org/10.1126/science.1116269.

Long, S.B., Tao, X., Campbell, E.B., MacKinnon, R., 2007. Atomic structure of a voltage-dependent $\mathrm{K}+$ channel in a lipid membrane-like environment. Nature 450, 376-382. http://dx.doi.org/10.1038/nature06265.

Lörinczi, É., Gómez-Posada, J.C., de la Peña, P., Tomczak, A.P., Fernández-Trillo, J. Leipscher, U., Stühmer, W., Barros, F., Pardo, L. a, 2015. Voltage-dependent gating of $\mathrm{KCNH}$ potassium channels lacking a covalent link between voltagesensing and pore domains. Nat. Commun. 6, 6672. http://dx.doi.org/10.1038 ncomms7672.

Mannuzzu, L.M., Moronne, M.M., Isacoff, E.Y., 1996. Direct physical measure of conformational rearrangement underlying potassium channel gating. Science 271, 213-216. http://dx.doi.org/10.1126/science.271.5246.213.

Mansoor, S.E., Dewitt, M.A., Farrens, D.L., 2010. Distance mapping in proteins using fluorescence spectroscopy: the tryptophan-induced quenching (TrIQ) method. Biochemistry 49, 9722-9731. http://dx.doi.org/10.1021/bi100907m.

Mansoor, S.E., Mchaourab, H.S., Farrens, D.L., 2002. Mapping proximity within proteins using fluorescence spectroscopy. A study of T4 lysozyme showing that tryptophan residues quench bimane fluorescence. Biochemistry 41, 2475-2484. http://dx.doi.org/10.1021/bi011198i.

Marmé, N., Knemeyer, J.P., Sauer, M., Wolfrum, J., 2003. Inter- and intramolecular fluorescence quenching of organic dyes by tryptophan. Bioconjug. Chem. 14, 1133-1139. http://dx.doi.org/10.1021/bc0341324.

Martens, J.R., Navarro-Polanco, R., Coppock, E. a., Nishiyama, A., Parshley, L. Grobaski, T.D., Tamkun, M.M., 2000. Differential targeting of shaker-like potassium channels to lipid rafts. J. Biol. Chem. 275, 7443-7446. http://dx.doi.org $10.1074 /$ jbc.275.11.7443.

Meera, P., Wallner, M., Song, M., Toro, L., 1997. Large conductance voltage- and calcium-dependent $\mathrm{K}+$ channel, a distinct member of voltage-dependent ion channels with seven $\mathrm{N}$-terminal transmembrane segments (S0-S6), an extracellular $\mathrm{N}$ terminus, and an intracellular (S9-S10) C terminus. Proc. Natl. Acad. Sci. U. S. A. 94, 14066-14071. http://dx.doi.org/10.1073/pnas.94.25.14066.

Minor, D.L., Findeisen, F., 2010. Progress in the Structural Understanding of Voltagegated Calcium Channel $(\mathrm{CaV})$ Function and Modulation. Channels, Austin. http://dx.doi.org/10.4161/chan.4.6.12867.

Miranda, P., Contreras, J.E., Wesch, D., Sigworth, F.J., Holmgren, M., Giraldez, T., 2012 State-dependent FRET reports large gating-ring motions in BK channels. Biophys. J. http://dx.doi.org/10.1016/j.bpj.2011.11.3735.

Mony, L., Berger, T.K., Isacoff, E.Y., 2015. A specialized molecular motion opens the Hv1 voltage-gated proton channel. Nat. Struct. Mol. Biol. 22, 283-290. http:// dx.doi.org/10.1038/nsmb.2978.

Moreno, J.D., Zhu, Z.I., Yang, P.-C., Bankston, J.R., Jeng, M.-T., Kang, C., Wang, L., Bayer, J.D., Christini, D.J., Trayanova, N.A., Ripplinger, C.M., Kass, R.S., Clancy, C.E., 2011. A computational model to predict the effects of class I anti-arrhythmic drugs on ventricular rhythms. Sci. Transl. Med. 3 http://dx.doi.org/10.1126/scitranslmed.3002588, 98ra83.

Murata, Y., Iwasaki, H., Sasaki, M., Inaba, K., Okamura, Y., 2005. Phosphoinositide phosphatase activity coupled to an intrinsic voltage sensor. Nature 435 , 1239-1243. http://dx doiorg/101038/nature03650.

Murata, Y., Okamura, Y., 2007. Depolarization activates the phosphoinositide phosphatase Ci-VSP, as detected in Xenopus oocytes coexpressing sensors of PIP2. J. Physiol. 583, 875-889. http://dx.doi.org/10.1113/jphysiol.2007.134775.

Muroi, Y., Chanda, B., 2009. Local anesthetics disrupt energetic coupling between the voltage-sensing segments of a sodium channel. J. Gen. Physiol. 133, 1-15. http://dx.doi.org/10.1085/jgp.200810103.

Nakajo, K., Kubo, Y., 2007. KCNE1 and KCNE3 stabilize and/or slow voltage sensing S4 segment of KCNQ1 channel. J. Gen. Physiol. 130, 269-281. http://dx.doi.org/ 10.1085/jgp.200709805.

Nekouzadeh, A., Rudy, Y., 2011. Continuum molecular simulation of large conformational changes during ion-channel gating. PLoS One 6, e20186. http:/ dx.doi.org/10.1371/journal.pone.0020186.

Nichols, C.G., 2006. KATP channels as molecular sensors of cellular metabolism. Nature 440, 470-476. http://dx.doi.org/10.1038/nature04711.

Noren, C.J., Anthony-Cahill, S.J., Griffith, M.C., Schultz, P.G., 1989. A general method for site-specific incorporation of unnatural amino acids into proteins. Sci. (80-. 244, 182-188. http://dx.doi.org/10.1126/science 2649980.

Oka, C., Cha, C.Y., Noma, A., 2010. Characterization of the cardiac $\mathrm{Na}+/ \mathrm{K}+$ pump by development of a comprehensive and mechanistic model. J. Theor. Biol. 265, 68-77. http://dx.doi.org/10.1016/j.jtbi.2010.04.028.

Osteen, J.D., Barro-Soria, R., Robey, S., Sampson, K.J., Kass, R.S., Larsson, H.P., 2012. Allosteric gating mechanism underlies the flexible gating of KCNQ1 potassium channels. Proc. Natl. Acad. Sci. http://dx.doi.org/10.1073/pnas.1201582109. 
Osteen, J.D., Gonzalez, C., Sampson, K.J., Iyer, V., Rebolledo, S., Larsson, H.P. Kass, R.S., 2010. KCNE1 alters the voltage sensor movements necessary to open the KCNQ1 channel gate. Proc. Natl. Acad. Sci. U. S. A. 107, 22710-22715. http:/ dx.doi.org/10.1073/pnas.1016300108.

Pantazis, A., Olcese, R., 2013. Cut-open oocyte voltage clamp technique., in. In: Encyclopedia of Biophysics. Roberts GCK. Springer Berlin Heidelberg pp. 406-413.

Pantazis, A., Olcese, R., 2012. Relative transmembrane segment rearrangements during BK channel activation resolved by structurally assigned fluorophorequencher pairing. J. Gen. Physiol. http://dx.doi.org/10.1085/jgp.201210807.

Pantazis, A., Savalli, N., Sigg, D., Neely, A., Olcese, R., 2014. Functional heterogeneity of the four voltage sensors of a human L-type calcium channel. Proc. Natl. Acad. Sci. 111, 18381-18386. http://dx.doi.org/10.1073/pnas.1411127112.

Perissinotti, L.L., Guo, J., De Biase, P.M., Clancy, C.E., Duff, H.J., Noskov, S.Y., 2015 Kinetic model for NS1643 drug activation of WT and L529I variants of Kv11. (hERG1) potassium channel. Biophys. J. 108, 1414-1424. http://dx.doi.org/ 10.1016/j.bpj.2014.12.056.

Piper, D.R., Varghese, A., Sanguinetti, M.C., Tristani-Firouzi, M., 2003. Gating currents associated with intramembrane charge displacement in HERG potassium channels. Proc. Natl. Acad. Sci. U. S. A. 100, 10534-10539. http://dx.doi.org 10.1073/pnas.1832721100.

Pless, S a, Ahern, C. a, 2013. Unnatural amino acids as probes of ligand-receptor interactions and their conformational consequences. Annu. Rev. Pharmacol. Toxicol. 53, 211-229. http://dx.doi.org/10.1146/annurev-pharmtox-011112 140343.

Post, R.L., Hegyvary, C., Kume, S., 1972. Activation by adenosine triphosphate in the phosphorylation kinetics of sodium and potassium ion transport adenosine triphosphatase. J. Biol. Chem. 247, 6530-6540.

Qin, N., Yagel, S., Momplaisir, M.-L., Codd, E.E., D'Andrea, M.R., 2002. Molecular cloning and characterization of the human voltage-gated calcium channe alpha(2)delta-4 subunit. Mol. Pharmacol. 62, 485-496. http://dx.doi.org 10.1016/0896-6273(91)90072-8

Rocheleau, J.M., Kobertz, W.R., 2008. KCNE peptides differently affect voltage sensor equilibrium and equilibration rates in KCNQ1 K+ channels. J. Gen. Physiol. 131 59-68. http://dx.doi.org/10.1085/jgp.200709816.

Rosenhouse-Dantsker, A., Noskov, S., Durdagi, S., Logothetis, D.E., Levitan, I., 2013 Identification of novel cholesterol-binding regions in Kir2 channels. J. Biol. Chem. 288, 31154-31164. http://dx.doi.org/10.1074/jbc.M113.496117.

Rudokas, M.W., Varga, Z., Schubert, A.R., Asaro, A.B., Silva, J.R., 2014. The Xenopus oocyte cut-open vaseline gap voltage-clamp technique with fluorometry. J. Vis. Exp. 1-11 http://dx.doi.org/10.3791/51040.

Rudy, Y., Silva, J.R., 2006. Computational biology in the study of cardiac ion channels and cell electrophysiology. Q. Rev. Biophys. 39, 57-116. http://dx.doi.org $10.1017 /$ S0033583506004227.

Ruscic, K.J., Miceli, F., Villalba-Galea, C.A., Dai, H., Mishina, Y., Bezanilla, F. Goldstein, S.A.N., 2013. IKs channels open slowly because KCNE1 accessory subunits slow the movement of S4 voltage sensors in KCNQ1 pore-forming subunits. Proc. Natl. Acad. Sci. U. S. A. 110, E559-E566. http://dx.doi.org 10.1073/pnas.1222616110

Sanguinetti, M.C., Curran, M.E., Zou, A., Shen, J., Spector, P.S., Atkinson, D.L. Keating, M.T., 1996. Coassembly of KvLQT1 and minK (IsK) proteins to form cardiac IKs potassium channel. Nature 384, 80-83. http://dx.doi.org/10.1038/ 384080a0.

Sanguinetti, M.C., Tristani-Firouzi, M., 2006. hERG potassium channels and cardiac arrhythmia. Nature 440, 463-469. http://dx.doi.org/10.1038/nature04710.

Schoppa, N.E., McCormack, K., Tanouye, M.A., Sigworth, F.J., 1992. The size of gating charge in wild-type and mutant Shaker potassium channels. Science 255 1712-1715. http://dx.doi.org/10.1126/science.1553560.

Schwinger, R.H.G., Bundgaard, H., Muller-ehmsen, J., Kjeldsen, K., 2003. The Na, K ATPase in the failing human heart. Cardiovasc. Res. 57, 913-920.

Seoh, S.A., Sigg, D., Papazian, D.M., Bezanilla, F., 1996. Voltage-sensing residues in the S2 and S4 segments of the Shaker K+ channel. Neuron 16, 1159-1167. http://dx.doi.org/10.1016/S0896-6273(00)80142-7.

Shah, M., Akar, F.G., Tomaselli, G.F., 2005. Molecular basis of arrhythmias. Circulation 112, 2517-2529. http://dx.doi.org/10.1161/CIRCULATIONAHA.104.494476.

Siefani, E., Bezanilla, F., 1998. Cut-open oocyte voltage-clamp technique. Methods Enzymol. 293, 300-318. http://dx.doi.org/10.1016/S0076-6879(98)93020-8.

Silva, J., Rudy, Y., 2005. Subunit interaction determines IKs participation in cardiac repolarization and repolarization reserve. Circulation 112, 1384-1391. http:/ dx.doi.org/10.1161/CIRCULATIONAHA.105.543306.

Silva, J.R., Goldstein, S. a N., 2013a. Voltage-sensor movements describe slow inactivation of voltage-gated sodium channels I: wild-type skeletal muscle $\mathrm{Na}(\mathrm{V}) 1.4$. J. Gen. Physiol. 141, 309-321. http://dx.doi.org/10.1085/ jgp.201210909

Silva, J.R., Goldstein, S. a N., 2013b. Voltage-sensor movements describe slow inactivation of voltage-gated sodium channels II: a periodic paralysis mutation in $\mathrm{Na}(\mathrm{V}) 1.4$ (L689I). J. Gen. Physiol. 141, 323-334. http://dx.doi.org/10.1085 jgp.201210910.

Silva, J.R., Pan, H., Wu, D., Nekouzadeh, A., Decker, K.F., Cui, J., Baker, N.A., Sept, D. Rudy, Y., 2009. A multiscale model linking ion-channel molecular dynamics and electrostatics to the cardiac action potential. Proc. Natl. Acad. Sci. 106, 11102-11106. http://dx.doi.org/10.1073/pnas.0904505106.

Silva, J.R., Rudy, Y., 2010. Molecular dynamics and computational methods: multiscale electrophysiology modeling: from atom to organ. J. Gen. Physiol. 135, 575-581. http://dx.doi.org/10.1085/jgp.200910358.

Smith, P.L., Yellen, G., 2002. Fast and slow voltage sensor movements in HERG potassium channels. J. Gen. Physiol. 119, 275-293. http://dx.doi.org/10.1085/ jgp.20028534.

Sun, W., Sarma, J.S., Singh, B.N., 1999. Electrophysiological effects of dronedarone (SR33589), a noniodinated benzofuran derivative, in the rabbit heart: comparison with amiodarone. Circulation 100, 2276-2281. http://dx.doi.org/ 10.1161/01.CIR.100.22.2276.

Thouta, S., Sokolov, S., Abe, Y., Clark, S.J., Cheng, Y.M., Claydon, T.W., 2014. Proline scan of the hERG channel S6 helix reveals the location of the intracellular pore gate. Biophys. J. 106, 1057-1069. http://dx.doi.org/10.1016/j.bpj.2014.01.035.

Trudeau, M.C., Zagotta, W.N., 2004. Dynamics of Ca2+-calmodulin-dependent inhibition of rod cyclic nucleotide-gated channels measured by patch-clamp fluorometry. J. Gen. Physiol. 124, 211-223. http://dx.doi.org/10.1085/ jgp.200409101.

Vaiana, A.C., Neuweiler, H., Schulz, A., Wolfrum, J., Sauer, M., Smith, J.C., 2003. Fluorescence quenching of dyes by tryptophan: interactions at atomic detail from combination of experiment and computer simulation. J. Am. Chem. Soc. 125, 14564-14572. http://dx.doi.org/10.1021/ja036082j.

Van Petegem, F., Clark, K.A., Chatelain, F.C., Minor, D.L., 2004. Structure of a complex between a voltage-gated calcium channel beta-subunit and an alpha-subunit domain. Nature 429, 671-675. http://dx.doi.org/10.1038/nature02588.

Van Slyke, A.C., Cheng, Y.M., Mafi, P., Allard, C.R., Hull, C.M., Shi, Y.P., Claydon, T.W., 2012. Proton block of the pore underlies the inhibition of hERG cardiac $\mathrm{K}+$ channels during acidosis. AJP Cell Physiol. http://dx.doi.org/10.1152/ ajpcell.00324.2011.

Varga, Z., Zhu, W., Schubert, A.R., Pardieck, J.L., Krumholz, A., Hsu, E.J., Zaydman, M. a., Cui, J., Silva, J.R., 2015. Direct measurement of cardiac Na ${ }^{+}$channel conformations reveals molecular pathologies of inherited mutations. Circ. Arrhythm. Electrophysiol. CIRCEP 115, 003155. http://dx.doi.org/10.1161/ CIRCEP.115.003155.

Wallner, M., Meera, P., Toro, L., 1996. Determinant for beta-subunit regulation in high-conductance voltage-activated and $\mathrm{Ca}(2+)$-sensitive $\mathrm{K}+$ channels: an additional transmembrane region at the $\mathrm{N}$ terminus. Proc. Natl. Acad. Sci. U. S. A. 93, 14922-14927. http://dx.doi.org/10.1073/pnas.93.25.14922.

Wang, K.W., Tai, K.K., Goldstein, S. a, 1996a. MinK residues line a potassium channel pore. Neuron 16, 571-577.

Wang, Q., Curran, M.E., Splawski, I., Burn, T.C., Millholland, J.M., VanRaay, T.J., Shen, J., Timothy, K.W., Vincent, G.M., de Jager, T., Schwartz, P.J., Toubin, J a, Moss, a J., Atkinson, D.L., Landes, G.M., Connors, T.D., Keating, M.T., 1996b. Positional cloning of a novel potassium channel gene: KVLQT1 mutations cause cardiac arrhythmias. Nat. Genet. 12, 17-23. http://dx.doi.org/10.1038/ng0196-

Wang, Q. Shen, J., Splawski, I., Atkinson, D., Li, Z., Robinson, J.L., Moss, A.J., Towbin, J.A., Keating, M.T., 1995. SCN5A mutations associated with an inherited cardiac arrhythmia, long QT syndrome. Cell 80, 805-811. http://dx.doi.org/ 10.1016/0092-8674(95)90359-3.

Yao, X., Parnot, C., Deupi, X., Ratnala, V.R.P., Swaminath, G., Farrens, D., Kobilka, B., 2006. Coupling ligand structure to specific conformational switches in the beta2-adrenoceptor. Nat. Chem. Biol. 2, 417-422. http://dx.doi.org/10.1038/ nchembio801.

Zagotta, W.N., Hoshi, T., Aldrich, R.W., 1994. Shaker potassium channel gating. III: evaluation of kinetic models for activation. J. Gen. Physiol. 103, 321-362. http:// dx.doi.org/10.1085/jgp.103.2.321.

Zahler, R., Sun, W., Ardito, T., Kashgarian, M., 1996. Na-K-ATPase alpha-isoform expression in heart and vascular endothelia: cellular and developmental regulation. Am. J. Physiol. 270, C361-C371.

Zaydman, M a, Kasimova, M. a, McFarland, K., Beller, Z., Hou, P., Kinser, H.E. Liang, H., Zhang, G., Shi, J., Tarek, M., Cui, J., 2014. Domain-domain interactions determine the gating, permeation, pharmacology, and subunit modulation of the IKs ion channel. Elife 3,1-19. http://dx.doi.org/10.7554/eLife.03606.

Zaydman, M.A., Silva, J.R., Delaloye, K., Li, Y., Liang, H., Larsson, H.P., Shi, J., Cui, J., 2013. Kv7.1 ion channels require a lipid to couple voltage sensing to pore opening. Proc. Natl. Acad. Sci. U. S. A. 110, 13180-13185. http://dx.doi.org/ $10.1073 /$ pnas.1305167110.

Zheng, J., 2006. Patch fluorometry: shedding new light on ion channels. Physiol. (Bethesda) 21, 6-12. http://dx.doi.org/10.1152/physiol.00041.2005.

Zheng, J., Zagotta, W.N., 2003. Patch-clamp fluorometry recording of conformational rearrangements of ion channels. Sci. STKE 2003, PL7. http://dx.doi.org/ 10.1126/stke.2003.176.pl7.

Zheng, J., Zagotta, W.N., 2000. Gating rearrangements in cyclic nucleotide-gated channels revealed by patch-clamp fluorometry. Neuron 28, 369-374. http:// dx.doi.org/10.1016/S0896-6273(00)00117-3.

Zühlke, R.D., Pitt, G.S., Deisseroth, K., Tsien, R.W., Reuter, H., 1999. Calmodulin supports both inactivation and facilitation of L-type calcium channels. Nature 399, 159-162. http://dx.doi.org/10.1038/20200. 